\title{
Acumulação de capacidades tecnológicas inovadoras na indústria de defesa em economias emergentes: a experiência dos projetos REMAX e TORC30 no Exército Brasileiro
}

\author{
Luiz Henrique Abreu Dal Bello ${ }^{1}$ \\ PAULO N. FIGUEIREDO ${ }^{2}$ \\ Thainá Ballero dos ANJos de Almeida ${ }^{2}$
}

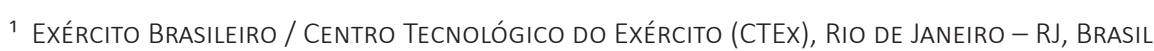 \\ 2 Fundação Getulio Vargas (FGV EBAPE) / Escola Brasileira de AdMinistração Pública e de EMPresas, RIO de JANEIRO - RJ, BRASIL
}

\section{Resumo}

Exame do processo de acumulação de capacidades tecnológicas para inovação e do papel dos processos subjacentes de aprendizagem tecnológica no contexto dos projetos Reparo de Metralhadora Automatizado X (REMAX) e Torre Operada Remotamente e Estabilizada para Canhão 30mm (TORC30) do Exército Brasileiro (EB), durante o período de 1999 a 2016. Baseando-se em evidências empíricas primárias e secundárias, em uma escala que identifica níveis de capacidades tecnológicas e em um modelo de processos de aprendizagem tecnológica, identificou-se durante o período estudado a evolução do nível de capacidades tecnológicas de básico para avançado. Essas capacidades tecnológicas se refletiram em atividades inovadoras: prototipagem, design e pesquisa e desenvolvimento (P\&D). Elas foram acumuladas por meio de esforços deliberados e eficazes em mecanismos de aprendizagem utilizados, de forma cíclica, em quatro etapas cumulativas: (i) preparação, (ii) aquisição de conhecimento externo, (iii) assimilação de conhecimento adquirido externamente e criação de conhecimento internamente e (iv) aplicação em atividades inovadoras. Portanto o estudo explora, do ponto de vista micro, a natureza e a dinâmica do processo de aprendizagem subjacente à acumulação de capacidades para inovação em uma indústria raramente estudada dessa perspectiva, particularmente no contexto brasileiro. A indústria de defesa possui um papel importante no desenvolvimento dos países. As inovações tecnológicas implementadas no âmbito desta indústria geram demandas importantes, tais como profissionais qualificados e atividades científicas e tecnológicas de diversos componentes do sistema de produção e de inovação em nível nacional, também oferecem grande potencial de aplicações múltiplas em outras indústrias, assim como na sociedade como um todo.

Palavras-chave: Acumulação de capacidades tecnológicas. Processos de Aprendizagem tecnológica. Inovação tecnológica. Indústria de defesa. Exército Brasileiro.

\section{Accumulation of technological capabilities in the defense industry in emerging economies: the experience of the REMAX and TORC30 projects in the Brazilian Army}

\begin{abstract}
This study examines the process of accumulation of technological capabilities for innovation and the role of the underlying processes of technological learning in the projects REMAX and TORC30 (Brazilian Army's weapons system)(TORC30), from 1999 to 2016. Based on primary and secondary empirical evidence, on a scale that identifies levels of technological capabilities and on a model of technological learning processes, the study identified the evolution of technological capabilities from a basic to an advanced level. These capabilities are reflected in innovative activities such as prototyping, design, and research and development (R\&D). They have been accumulated through deliberate efforts and activated learning mechanisms used cyclically in four cumulative steps: (i) preparation, (ii) acquisition of external knowledge, (iii) assimilation of externally acquired knowledge and knowledge internally created, and (iv) application in innovative activities. Therefore, the study explores, from the micro point of view, the nature and learning process underlying the capacity of accumulating innovation in an industry where this perspective is rarely applied, particularly in the Brazilian context. The defense industry plays an important role in the development of countries. The technological innovations implemented within this industry generate important demands, such as professionals and scientific and technological activities of various components of the national production and innovation system, as well as the potential application of such innovations, in several ways, in other industries, and in society as a whole.
\end{abstract}

Keywords: Accumulation of technological capabilities. Technology Learning Processes. Technological innovation. Defense industry. Brazilian army.

Acumulación de capacidades tecnológicas innovadoras en la industria de defensa en economías emergentes: la experiencia de los proyectos REMAX y TORC30 en el Ejército Brasileño

\section{Resumen}

Examen del proceso de acumulación de tecnología tecnológica para innovación y del papel de los procesos subyacentes de aprendizaje tecnológico en el contexto de los proyectos Reparación automática de ametralladoras X (REMAX) y Torre operada remotamente y estabilizada para cañón de 30 mm (TORC30) del Ejército Brasileño (EB) durante el período de 1999 a 2016. Basado en evidencias empíricas primarias y secundarias en una escala que identifica los niveles de uso de tecnologías tecnológicas y en un modelo de procesos de aprendizaje tecnológico, se identificó durante el período estudiado la evolución del nivel de capacidades tecnológicas de básico a avanzado. Estas capacidades tecnológicas se reflejaron en actividades innovadoras: creación de prototipos, diseño e investigación y desarrollo (I + D). Se han acumulado a través de esfuerzos deliberados y mecanismos de aprendizaje activados utilizados cíclicamente en cuatro pasos acumulativos: (i) preparación, (ii) adquisición de conocimiento externo, (iii) asimilación de conocimiento adquirido externamente y creación de conocimiento internamente, y (iv) aplicación en actividades innovadoras. Por lo tanto, el estudio explora del punto de vista micro la naturaleza y el proceso de aprendizaje subyacente a la acumulación de capacidades para innovación en una industria raramente estudiada desde esta perspectiva, particularmente en el contexto brasileño. La industria de defensa juega un papel importante en el desarrollo de los países. Las innovaciones tecnológicas implementadas dentro de esta industria generan demandas importantes, tales como profesionales cualificados y actividades científicas y tecnológicas de diversos componentes del sistema de producción e innovación a nivel nacional, así como ofrecen gran potencial de aplicaciones múltiples en otras industrias, así como en la sociedad en general.

Palabras clave: Acumulación de capacidades tecnológicas. Procesos de aprendizaje tecnológico. Innovación tecnológica. Industria de defensa. Ejército Brasileño. 


\section{INTRODUÇÃO}

A maneira como empresas acumulam capacidades tecnológicas é um dos fatores decisivos que influenciam a competitividade industrial e o desenvolvimento econômico dos países. As capacidades tecnológicas constituem um estoque de recursos - também chamado de ativo cognitivo e estratégico - e a aprendizagem tecnológica é um processo constituído por vários fluxos de conhecimentos externos e internos, que permitem que organizações e países acumulem suas capacidades tecnológicas (FIGUEIREDO, 2015).

A indústria de defesa foi selecionada como foco de análise deste estudo, pois, apesar de ser alvo de uma visão de que desempenha papel restrito ao uso de armas e guerra, oferece amplas oportunidades para o desenvolvimento tecnológico e inovação. A importância da indústria de defesa está, naturalmente, na garantia da segurança nacional e do crescimento econômico que ela proporciona ao país. Porém a indústria possui uma peculiaridade que torna o seu papel ainda mais relevante: a acumulação de capacidades tecnológicas da indústria de defesa proporciona um transbordamento tecnológico - denominado spin-off na literatura - para as demais indústrias do país. Ou seja, as tecnologias desenvolvidas na indústria de defesa podem possuir aplicação dual e ser utilizadas também na indústria civil, como a internet, a telefonia celular e o sistema de geoposicionamento por satélite (GPS) (DUNNE e BRADDON, 2008). Muitas tecnologias comerciais de sucesso do século XX, por exemplo, podem apresentar, em suas origens, projetos e programas financiados com fundos de defesa (MOLAS-GALLART, 1997).

O transbordamento tecnológico não ocorre de modo proposital, a menos que seja estimulado por meio de políticas públicas orientadas para dupla utilização de tecnologias (DUNNE e BRADDON, 2008). A tecnologia de uso dual pode ser definida como uma instância especial da transferência de tecnologia entre usuários, que ocorre quando uma tecnologia, desenvolvida para uso militar, é transferida para o uso civil (MOLAS-GALLART, 1997).

Este estudo investigou o papel do processo de aprendizagem tecnológica na acumulação de capacidades tecnológicas para inovação nos projetos desenvolvidos pelo Exército Brasileiro (EB): Reparo de Metralhadora Automatizado X (REMAX), um sistema de armas com acionamento elétrico, que pode ser integrado a uma viatura sobre rodas ou sobre lagartas; e TORC30, um sistema de armas similar ao REMAX, para uma categoria superior de armamento, utilizando um canhão calibre $30 \mathrm{~mm}$.

O estudo aqui apresentado foi estruturado para responder à seguinte questão: como o EB construiu e acumulou capacidades tecnológicas para implementar os projetos inovadores REMAX e TORC30? Para examinar esta questão de pesquisa, o estudo baseou-se em evidências preponderantemente primárias sobre as várias atividades inovadoras e os diversos mecanismos subjacentes de aprendizagem tecnológica no âmbito dos projetos acima mencionados durante o período de 1999 a 2006.

Este estudo está organizado da seguinte maneira: a seção 2 apresenta um panorama da indústria de defesa nacional e internacional; na seção 3 tem-se a base conceitual da pesquisa; na seção 4, o exame dos elementos do método do estudo; a seção 5 contém as evidências do estudo e dá base à resposta à questão do estudo; a seção 6 traz as discussões e conclusões.

\section{Breve Panorama da Indústria de Defesa}

Esta seção apresenta uma breve discussão sobre a importância da indústria de defesa para o desenvolvimento econômico dos países, bem como um breve panorama sobre indústria de defesa no Brasil.

\section{A importância da indústria de defesa para o desenvolvimento econômico dos países}

A indústria de defesa é considerada altamente relevante para o desenvolvimento tecnológico e aumento de produtividade nos países. Nos últimos anos, vem desempenhando um papel cada vez mais presente na agenda estratégica de vários países, incluindo-se o Brasil. A indústria de defesa é considerada uma das mais importantes dentro da estrutura produtiva das economias avançadas e também das grandes economias emergentes (particularmente Rússia, China e Índia) (BRASIL, 2016a). Leske (2015) reitera que a indústria de defesa mantém relação estreita com a Ciência, Tecnologia e Inovação (CT\&I) e é tida como geradora de potenciais transbordamentos para outras áreas, sendo estimulada em muitos países, principalmente nos Estados Unidos.

Para examinar a indústria, é preciso antes clarificar alguns termos e conceitos que a envolvem. Entende-se segurança como a condição que permite ao país preservar sua soberania e integridade territorial, promover seus interesses nacionais, livre de pressões e ameaças, e garantir aos cidadãos o exercício de seus direitos e deveres constitucionais (BRASIL, 2012). Pode-se considerar defesa uma atividade típica do Estado, pois sua missão é constituí-lo e preservá-lo como ator (CORRÊA, 2014). Defesa nacional é o conjunto de medidas e ações do Estado, com ênfase no campo militar, para a defesa do território, da soberania e dos interesses nacionais contra ameaças preponderantemente externas, potenciais ou manifestas (BRASIL, 2012). 
Ravara (2001) contextualiza defesa como uma indústria estratégica, cujos produtos podem ser cruciais para a defesa nacional, razão pela qual, diferentemente de outras indústrias, é a política de segurança e defesa que, em vários graus, dita também a política nacional de armamento. $O$ autor enfatiza ainda que são considerações políticas, estratégicas e de segurança que entram em cena e prevalecem na determinação das condições em que a indústria opera e na procura dos seus produtos.

Considera-se do interesse estratégico nacional a manutenção de uma expressão mínima suficiente de uma indústria de defesa, não só para a sustentação das forças armadas, mas também pelo seu contributo ímpar para o desenvolvimento de competências em tecnologias de ponta (RAVARA, 2001). Dosi (2006) apresenta o caso notável dos Estados Unidos, onde os transbordamentos tecnológicos da indústria de defesa resultaram de maneira extremamente positiva no desenvolvimento de novas tecnologias e inovação, inclusive no setor civil, como a internet, os semicondutores (DOSI, 2006), o sistema de geoposicionamento por satélite (GPS), a telefonia celular, o raio infravermelho etc.

Segundo Leske (2013), existe uma série de canais por meio dos quais a Base Industrial de Defesa (BID) pode afetar a economia positivamente, gerando empregos, mas, também, negativamente, ao desviar recursos de outras áreas, como saúde e educação. Por exemplo, um país com altas taxas de crescimento pode escolher dois caminhos distintos: (i) reforçar sua proteção contra ameaças externas ou internas, aumentando os gastos em defesa; ou (ii) desviar recursos da defesa para outros setores do país, diminuindo seus gastos (JOERDING, 1986; KOLLIAS, 1997).

Estima-se que o total das despesas militares mundiais tenha atingido US\$1,739 bilhão em 2017, o nível mais alto desde o fim da Guerra Fria (TIAN, FLEURANT, KUIMOVA et al., 2018). A Tabela 1 mostra o ranking dos 15 países com os maiores orçamentos de defesa do mundo em 2017. Os Estados Unidos dominam os gastos militares mundiais com US\$ 610 bilhões. O orçamento brasileiro ocupa o $11^{\circ}$ lugar no ranking, no período.

A Figura 1 apresenta despesas militares por país entre 2000 e 2017, em percentagem do Produto Interno Bruto (PIB), dos países selecionados. Os Estados Unidos possuem a maior taxa. Percebe-se a evolução da Coreia, que terminou o ano de $2017 \mathrm{com}$ a segunda maior taxa entre os países presentes na amostra. Evidencia-se a evolução de algumas economias emergentes, como China, Índia e Brasil. Isso pode ser explicado pelo fato de algumas economias emergentes buscarem reduzir sua dependência de outras nações, melhorar sua segurança nacional e incentivarem o desenvolvimento de suas indústrias locais, adquirindo capacidades tecnológicas relacionadas à defesa (BITZINGER, 2013). Contudo, nota-se que o Brasil ainda possui uma taxa baixa quando comparada a outros países.

Tabela 1

Ranking dos 15 países com maiores orçamentos de defesa no mundo em 2017

\begin{tabular}{|c|c|c|c|}
\hline Posição & País & $\begin{array}{c}\text { Orçamento (US\$ bilhões } \\
\text { correntes) }\end{array}$ & $\%$ ao $\mathrm{PIB}$ \\
\hline 1 & EUA & 610 & 3,1 \\
\hline 2 & China & 228 & 1,9 \\
\hline 3 & Arábia Saudita & 69.4 & 10 \\
\hline 4 & Rússia & 66.3 & 4,3 \\
\hline 5 & Índia & 63.9 & 2,5 \\
\hline 6 & França & 57.8 & 2,3 \\
\hline 7 & Reino Unido & 47.2 & 1,8 \\
\hline 8 & Japão & 45.4 & 0,9 \\
\hline 9 & Alemanha & 44.3 & 1,2 \\
\hline 10 & Coreia do Sul & 39.2 & 2,6 \\
\hline 11 & Brasil & 29.3 & 1,4 \\
\hline 12 & Itália & 29.2 & 1,5 \\
\hline 13 & Austrália & 27.5 & 2,0 \\
\hline 14 & Canadá & 20.6 & 1,3 \\
\hline 15 & Turquia & 18.2 & 2,2 \\
\hline \multicolumn{2}{|c|}{ Subtotal dos 15 maiores } & 1,396 & - \\
\hline \multicolumn{2}{|c|}{ Total mundial } & 1,739 & 2.2 \\
\hline
\end{tabular}

Fonte: Adaptada de SIPRI Databases (2019). 
Figura 1

Despesas militares por país em percentagem do PIB, para países selecionados (2000-2017)

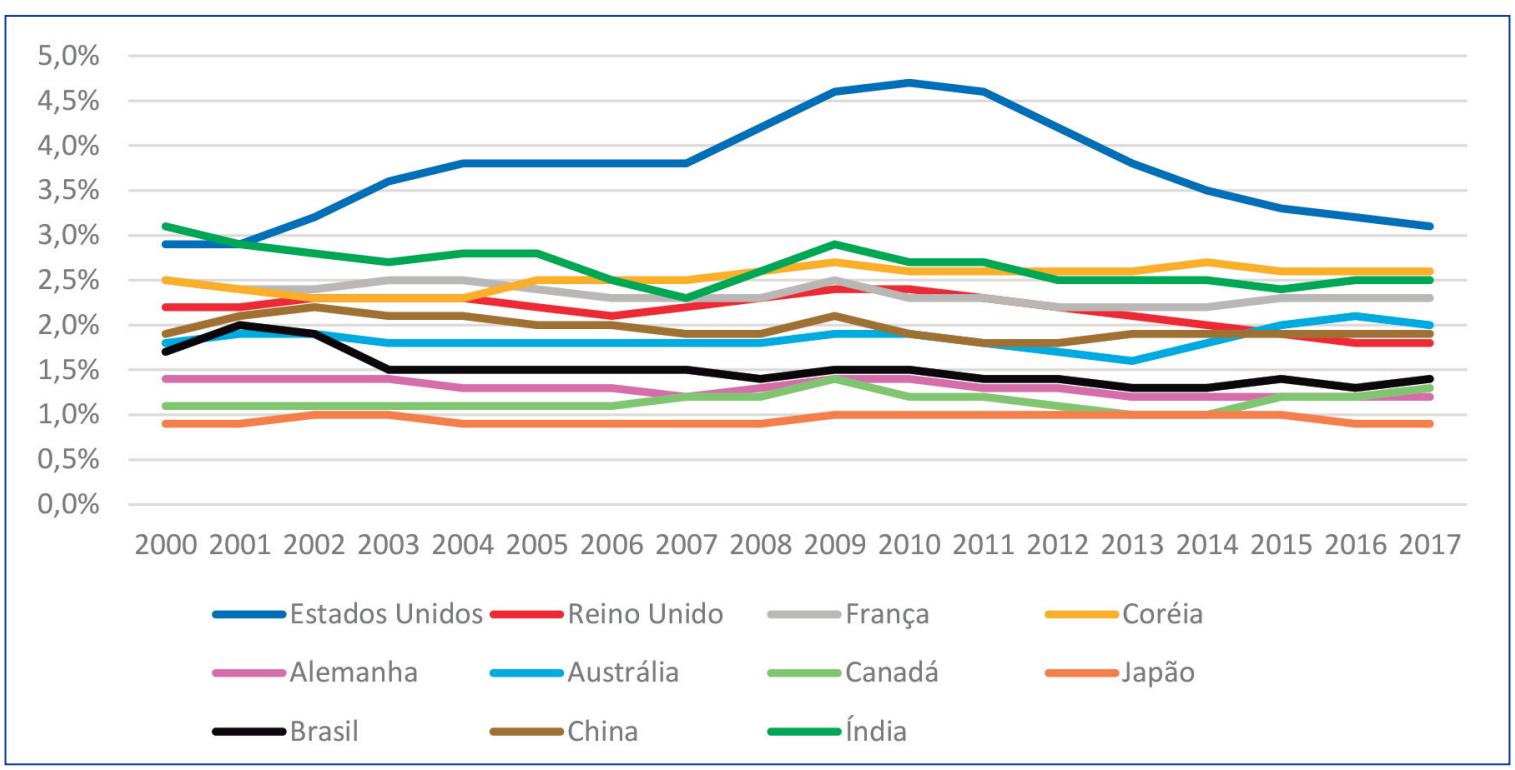

Fonte: Adaptada de SIPRI Databases (2019).

A Figura 2 mostra a média do percentual da dotação orçamentária governamental, entre 2000 e 2013, em P\&D dos setores civil e de defesa de países selecionados. Os Estados Unidos lideram o percentual de investimento em defesa, sendo, inclusive, o único país da amostra em que os investimentos na indústria dominam os gastos totais do país. Percebe-se que o Brasil ainda apresenta baixo percentual de investimento na indústria.

Figura 2

Média do percentual da dotação orçamentária governamental em P\&D dos setores civil e de defesa para países selecionados (2000-2013)

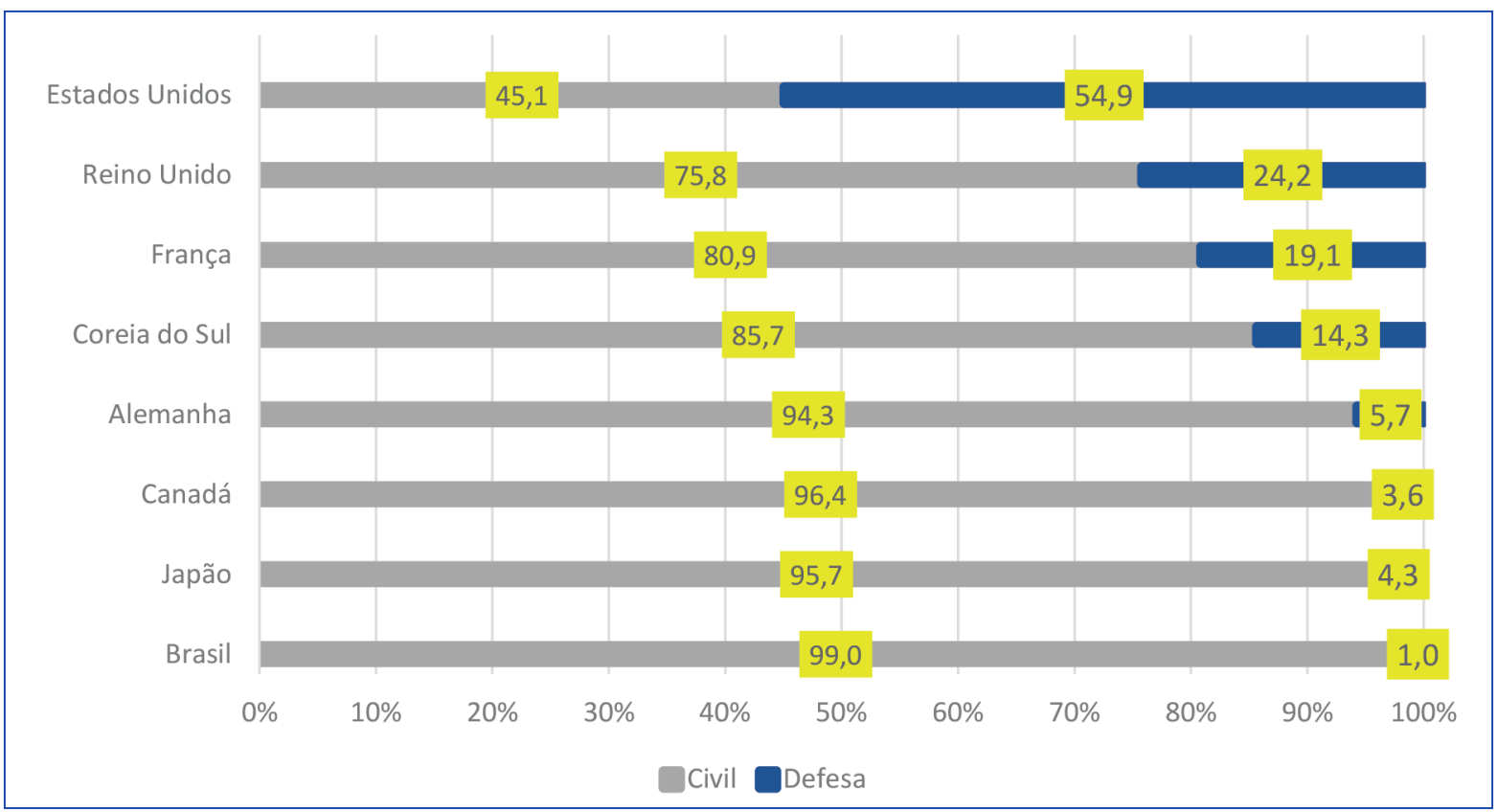

Fonte: Adaptada de OECD (2018) e Brasil (2016b). 
A Tabela 2 mostra as maiores empresas de defesa do mundo, distribuídas por país/região em 2016. A indústria de defesa está concentrada em poucos países, refletindo tanto a concentração da demanda como o elevado diferencial de capacitação produtiva, tecnológica e empresarial das diferentes nações (BRASIL, 2016c). Percebe-se a decisiva influência dos EUA, dotando 44 empresas, e da União Europeia, com 24 empresas. Contudo, como já foi dito, as economias emergentes estão buscando reduzir sua dependência de outras nações, o que é refletido no avanço dos países que compõem o BRICS, somando 19 empresas. Das dezoito, treze são da Rússia, cinco são da Índia e apenas uma é do Brasil.

A Rússia é o único país emergente que possui uma estrutura produtiva compativel com a atual demanda de suas Forças Armadas, pois, apesar dos retrocessos dos anos 1990, ainda preserva grande parte da capacitação tecnológica e produtiva do antigo complexo industrial-militar soviético (BRASIL, 2016c). Na Índia e no Brasil, as limitações das respectivas indústrias de defesa são ainda maiores, particularmente nos setores que envolvem o domínio de tecnologias avançadas (DOWNES, 2009). Contudo, mesmo com suas deficiências, os países do BRICS vêm aumentando participação no comércio mundial como fabricantes de Produtos Estratégicos de Defesa (PED).

Tabela 2

Maiores empresas de defesa: distribuição por país/região, 2016

\begin{tabular}{cccc}
\hline Países & $\begin{array}{c}\text { Número de } \\
\text { Empresas }\end{array}$ & $\begin{array}{c}\text { Faturamento } \\
\text { (US\$ milhões) }\end{array}$ & Emprego Total \\
\hline EUA & 44 & 666,250 & 6340 \\
União Europeia & 24 & 270,785 & 863710 \\
BRICS & 18 & 49,140 & 393660 \\
Outros & 29 & 258,614 & 284120 \\
\hline
\end{tabular}

Fonte: Dados do Sipri (2016).

Segundo Brasil (2016a), a quase totalidade das empresas de defesa listadas entre as maiores do mundo também atua fora da área de defesa, aproveitando a dualidade civil-militar em diferentes proporções. Na verdade, para a maioria das empresas, o faturamento é proveniente, em sua totalidade, do mercado civil, excepcionalmente se consegue obter um faturamento acima de 50\% somente com a venda de produtos de defesa. Empresas como Lockheed Martin, Raytheon, BAE Systems e Northrop Grumman, que ocupam as primeiras posições no ranking, conseguem obter acima de $80 \%$ de seu faturamento advindo da venda de armas. Contudo, empresas como Boeing, Thales e Airbus obtêm faturamento abaixo de $50 \%$ relativo a origem exclusiva da defesa. A Embraer, única empresa brasileira que compõe a lista, possui apenas $15 \%$ do seu faturamento obtido pela venda de armas.

\section{A indústria de defesa no Brasil: breve panorama}

No Brasil, o livro Estratégia Nacional de Defesa (BRASIL, 2012) define a BID como conjunto integrado de empresas públicas e privadas, e de organizações civis e militares, que realizem ou conduzam pesquisa, projeto, desenvolvimento, industrialização, produção, reparo, conservação, revisão, conversão, modernização ou manutenção de produtos de defesa (Prode) no País. Em virtude dos esforços em estimular a indústria de defesa do País, na Estratégia Nacional de Defesa (END), foram mapeadas empresas privadas que representam importância estratégica para o fomento da defesa no Brasil. São 95 empresas nacionais credenciadas, divididas em: 19 empresas de defesa (ED) e 76 empresas estratégicas de defesa (EED) (ABIMDE, 2019).

O Stockholm International Peace Research Institute (SIPRI, 2015) divide os PED nas seguintes categorias: aeronaves, mísseis, espaço, navios, veículos militares, sistemas eletrônicos, sistemas de artilharia, armas leves; além de três categorias transversais, motores, componentes e serviços. Para Negrete, Leite, Leske et al. (2016), os principais segmentos ocupados pelas empresas brasileiras mapeadas na BID são: Armas e Munições Leves e Pesadas e Explosivos, Sistemas Eletrônicos e Sistemas de Comando e Controle, Plataforma Naval Militar, Propulsão Nuclear, Plataforma Terrestre Militar, Plataforma Aeronáutica Militar, Sistemas Espaciais voltados para Defesa e Equipamentos de Uso Individual.

A Figura 3 mostra a evolução orçamentária dos investimentos no Ministério da Defesa do Brasil, entre 2005 e 2017. Nos últimos anos, os recursos direcionados à defesa nacional obtiveram um incremento significativo, saltando de $R \$ 33$ bilhões, em 2005, para R\$ 93 bilhões, em 2017, sendo 43\% destinados ao Exército Brasileiro (BRASIL, 2016c). Tal aumento pode ser explicado, em 
parte, pela criação da Estratégia Nacional de Defesa, que permitiu a retomada da indústria de defesa como tema de enfoque de investimentos no Brasil (BRASIL, 2012). No mesmo período, o Índice Nacional de Preços ao Consumidor Amplo (IPCA) alcançou 5,69\% em 2005. Sua mais alta variação, no período, ocorreu em 2015, com 10,67\%, terminando com 2,95\%, em 2017 (BRASIL, 2018a). Em 2016, os investimentos foram divididos em: despesas de pessoal (76\%), despesas de custeio (14\%), investimentos em projetos (8\%) e dívidas (2\%), sendo R\$ 906 milhões destinados à P\&D do EB, para o desenvolvimento de projetos como Sisfron, Astros 2020 e os Blindados Guarani (BRASIL, 2018b). No entanto, o crescimento nominal do orçamento de defesa do País não significou aumento no seu percentual em relação ao PIB brasileiro.

Figura 3

Evolução dos investimentos no Ministério de Defesa do Brasil, em R\$ milhões (2005-2017)

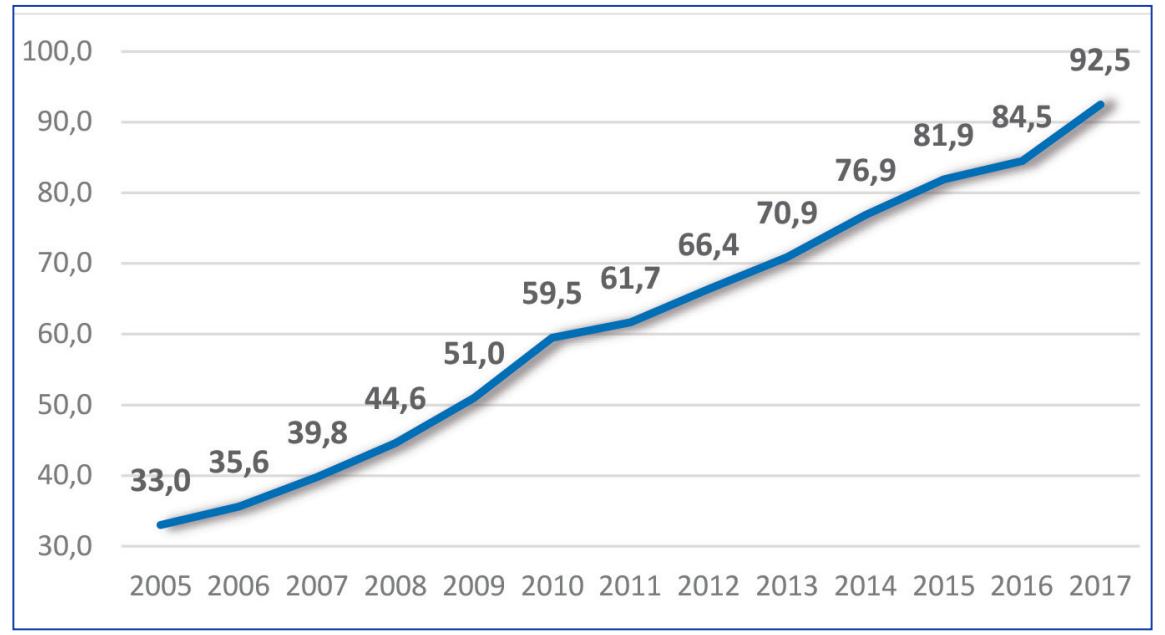

Fonte: Adaptada de Brasil (2019).

A Tabela 3 apresenta a evolução do comércio exterior de equipamentos militares do Brasil por categoria de produto (em US\$ milhões) entre 1993 e 2012. O País possui um baixo volume de exportações e ocupa uma posição bastante tímida no mercado internacional, ocupando o $25^{\circ}$ lugar no ranking de países com maior volume exportado na indústria (CORREA FILHO, BARROS, CASTRO et al., 2013). Contudo se constata que a diversidade de exportações é baixa. Isso pode ser explicado pelo fato de as empresas Embraer e Forjas Taurus deterem os títulos de maiores exportadoras nacionais atuais com aeronaves e armamentos leves (CUNHA e NOGUEIRA, 2017).

Tabela 3

Evolução do comércio de equipamentos militares do Brasil por categoria de produto (em US\$ milhões), entre 1993 e 2012

\begin{tabular}{|c|c|c|c|c|}
\hline Categoria de Produto & 1993-1997 & $1998-2002$ & 2003-2007 & 2008-2012 \\
\hline \multicolumn{5}{|c|}{ Exportações - acumulado (US\$ milhões) } \\
\hline Aeronaves & 115 & 16 & 134 & 312 \\
\hline Veículos Blindados & 54 & 2 & 0 & 11 \\
\hline Artilharia & 0 & 17 & 0 & 17 \\
\hline Mísseis & 0 & 0 & 0 & 25 \\
\hline Navios & 0 & 0 & 10 & 11 \\
\hline Sensores & 0 & 8 & 0 & 8 \\
\hline Motores & 0 & 0 & 0 & 0 \\
\hline Outros & 0 & 0 & 0 & 0 \\
\hline Total & 169 & 42 & 144 & 384 \\
\hline
\end{tabular}


Continuação

\begin{tabular}{|c|c|c|c|c|}
\hline Categoria de Produto & 1993-1997 & $1998-2002$ & $2003-2007$ & 2008-2012 \\
\hline \multicolumn{5}{|c|}{ Importações - acumulado (US\$ milhões) } \\
\hline Aeronaves & 254 & 469 & 316 & 560 \\
\hline Veículos Blindados & 114 & 64 & 1 & 400 \\
\hline Artilharia & 36 & 34 & 1 & 0 \\
\hline Mísseis & 182 & 108 & 70 & 164 \\
\hline Navios & 957 & 641 & 190 & 157 \\
\hline Sensores & 33 & 221 & 170 & 80 \\
\hline Motores & 61 & 31 & 54 & 64 \\
\hline Outros & 0 & 9 & 0 & 0 \\
\hline Total & 1.637 & 1.573 & 801 & 1.424 \\
\hline \multicolumn{5}{|c|}{ Saldo comercial - acumulado (US\$ milhões) } \\
\hline Aeronaves & (139) & $(453)$ & $(182)$ & (248) \\
\hline Veículos Blindados & $(60)$ & $(62)$ & $(1)$ & (389) \\
\hline Artilharia & (36) & (17) & (1) & 17 \\
\hline Mísseis & $(182)$ & (108) & (70) & (139) \\
\hline Navios & (957) & $(641)$ & $(180)$ & $(146)$ \\
\hline Sensores & (33) & $(213)$ & (170) & $(72)$ \\
\hline Motores & (61) & (31) & $(54)$ & (64) \\
\hline Outros & 0 & (9) & 0 & 0 \\
\hline Total & (1.468) & (1.531) & (657) & $(1.040)$ \\
\hline
\end{tabular}

Fonte: Correa Filho, Barros, Castro et al. (2013).

\section{Base Conceitual do Estudo}

Esta seção apresenta a base conceitual do estudo, delimitando conceitos básicos e modelos analíticos que dão sustentação às evidências da pesquisa. A seção é dividida em outras duas subseções. Em primeiro lugar, será analisada a acumulação de capacidades tecnológicas para a inovação. Subsequentemente, será estudado o papel da aprendizagem tecnológica para a acumulação de capacidades tecnológicas.

\section{Acumulação de capacidades tecnológicas para inovação: perspectiva de organizações e empresas de economias emergentes}

Há diversas definições para o termo capacidade tecnológica (ANDRADE e FIGUEIREDO, 2008). Capacidades tecnológicas podem ser definidas como os recursos necessários - contidos em indivíduos (aptidões, conhecimentos e experiência) e sistemas organizacionais (BELL e PAVITT, 1993) - para gerar e gerir a mudança tecnológica. Capacidade tecnológica também pode ser entendida como o resultado da interação entre o esforço de P\&D e os recursos de P\&D disponíveis em relação à comercialização esperada de produtos futuros (LEE e LIM, 2001).

Para Miranda e Figueiredo (2010), capacidade tecnológica pode ser considerada como os recursos necessários para gerar e gerenciar atividades inovadoras em produtos, processos, sistemas organizacionais e equipamentos. Especialmente no contexto de países emergentes, são vistas como um conjunto de recursos de natureza cognitiva, intangível, mas capazes de definir seu desempenho distintivo no mercado; tendo-as por base, as empresas são capazes de realizar atividades de produção (de bens e serviços) e de inovação (FIGUEIREDO, 2015).

Uma das principais características das empresas de economias emergentes é a deficiência inicial de recursos ou capacidades tecnológicas. Em geral, a entrada dessas empresas na indústria ocorre tardiamente, ou seja, muito tempo depois daquelas empresas líderes de países tecnologicamente e industrialmente avançados. Na maioria dos casos, elas iniciam suas atividades à base de tecnologias adquiridas de outros países e no início de suas atividades Ihes faltam, inclusive, capacidades tecnológicas básicas (FIGUEIREDO, 2015, p. 38). 
Entende-se que a acumulação das capacidades tecnológicas ocorre em "estágios" que podem evoluir entre os níveis básico, intermediário e avançado (BELL e PAVITT, 1995; FIGUEIREDO, 2001). Pode-se considerar que a inovação, como um todo, consiste em um processo contínuo e não em episódios esporádicos; tal processo envolve a realização de diferentes tipos de atividade e necessita de estoques de capacidade acumulados por processos subjacentes de aprendizagem, específicos às empresas e a outros tipos de organização (NELSON e WINTER, 1985; DOSI, 1988). Para Miranda e Figueiredo (2010), essa abordagem da inovação coaduna-se com o Manual de Oslo (OECD, 2002), que demonstra distinções entre as capacidade inovadoras que são "novas à empresa", "novas ao mercado" e "novas para o mundo". A Figura 4 apresenta a escala de níveis de capacidades tecnológicas utilizada neste estudo. Desse modo, diferenciam-se: capacidade de produção e quatro níveis de capacidades tecnológicas inovadoras. Esse modelo foi utilizado para coletar evidências e analisar a origem e a trajetória da acumulação de capacidades tecnológicas pelo EB durante a implementação dos projetos.

\section{Figura 4}

\section{Escala de níveis de capacidade tecnológica}

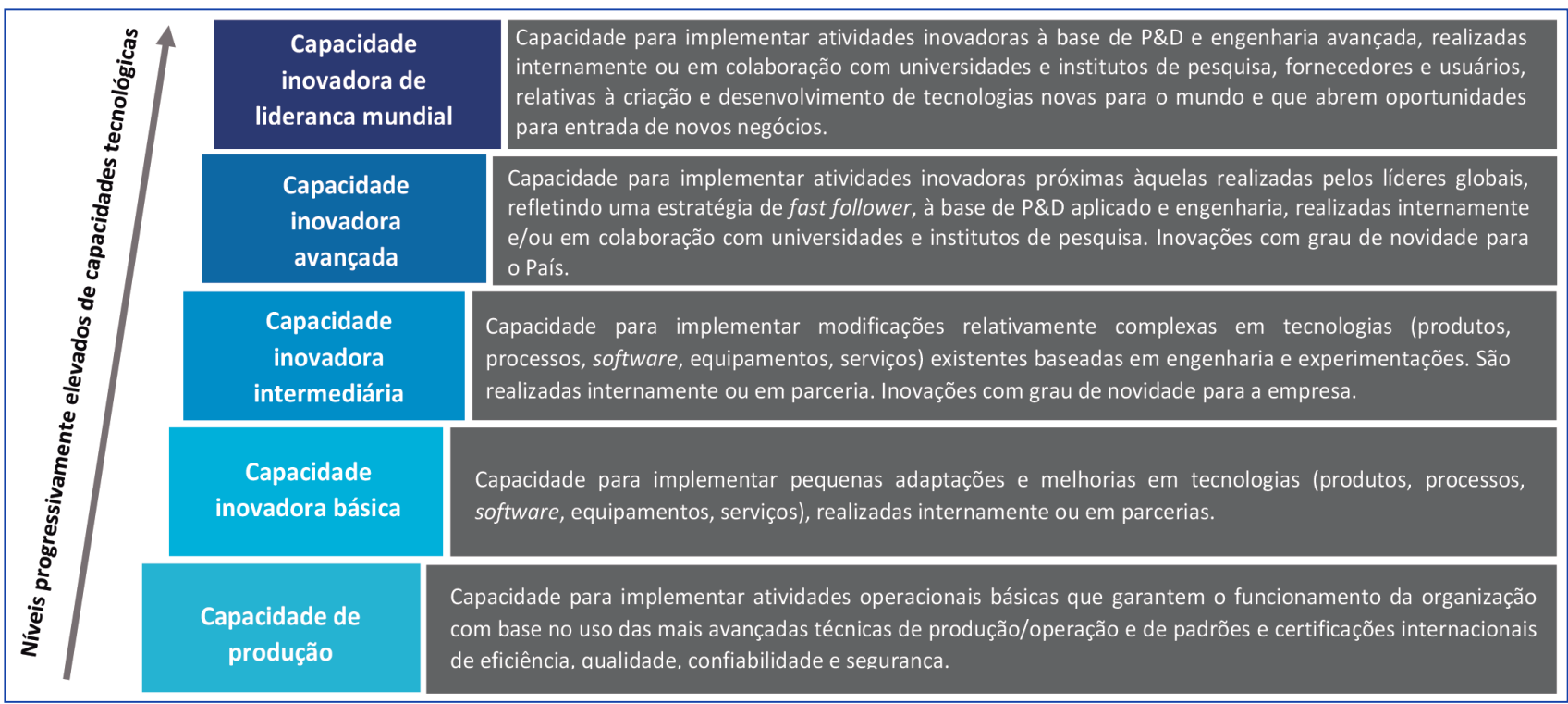

Fonte: Figueiredo, Pinheiro, Cabral et al. (2018).

\section{Papel da aprendizagem tecnológica no processo de acumulação de capacidades tecnológicas para inovação}

Considera-se aprendizagem tecnológica um processo constituído por vários fluxos de conhecimento externos e internos que permitem organizações e países acumularem suas capacidades tecnológicas (FIGUEIREDO, 2015). Este artigo utiliza a definição de Figueiredo (2015), que identifica três tipos de mecanismo de aprendizagem: (i) intraempresariais (alavancagem de conhecimento externo e geração interna de saber tecnológico); (ii) interempresariais (fluxos de saber entre subsidiárias de empresas multinacionais, localizadas no Brasil e suas empresas-mães e empresas-irmãs); e (iii) interorganizacionais (ligações de saber entre as empresas e as demais organizações do sistema de inovação). A Figura 5 mostra o relacionamento entre a aprendizagem tecnológica, o processo de acumulação de capacidades tecnológicas para inovação e como esse processo influencia diretamente os indicadores de performance competitiva da empresa. Importante salientar que o presente estudo tem como foco analisar apenas o processo de acumulação de capacidades tecnológicas e o papel dos subjacentes processos dos mecanismos de aprendizagem tecnológica, como explicitado na Figura 5. 
Figura 5

Relacionamento entre aprendizagem tecnológica e o processo de acumulação de capacidades tecnológicas

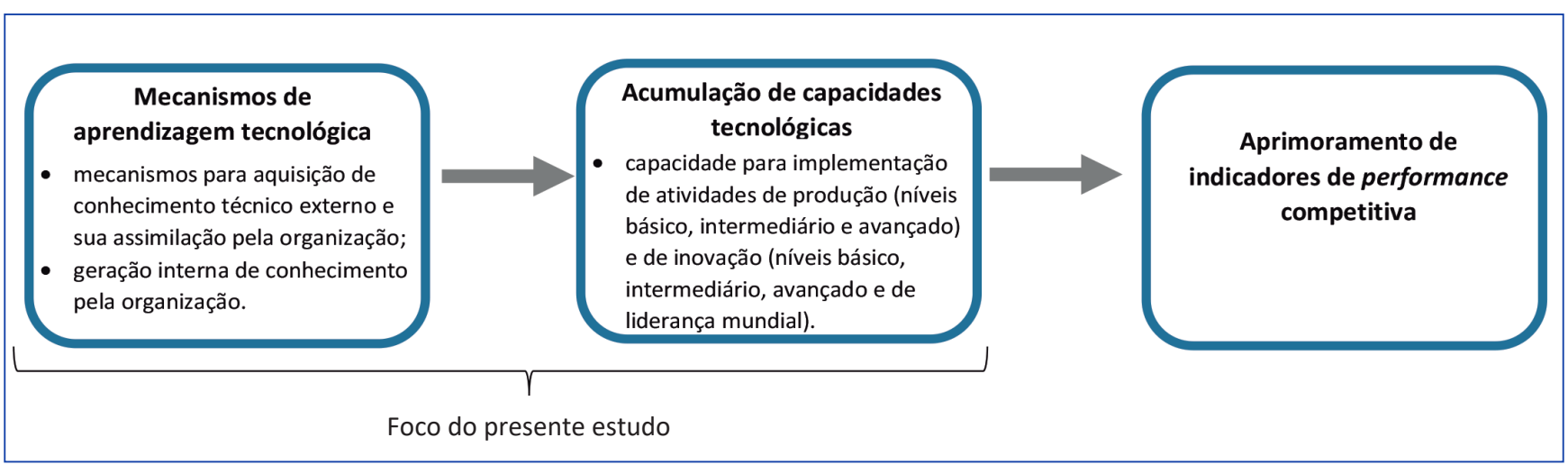

Fonte: Figueiredo (2015).

A Figura 6 apresenta o modelo de ciclo de aprendizagem tecnológica subjacente à acumulação de capacidades tecnológicas inovadoras, adotado no estudo. Ele foi desenvolvido segundo os conceitos apresentados por Kim (1998) para a trajetória de aprendizagem tecnológica em projetos realizados em países de economia emergente. O modelo evidencia que tais projetos são constituídos por quatro etapas: preparação, aquisição, assimilação e aplicação.

Figura 6

Modelo de ciclo de aprendizagem tecnológica subjacente à acumulação de capacidades tecnológicas inovadoras

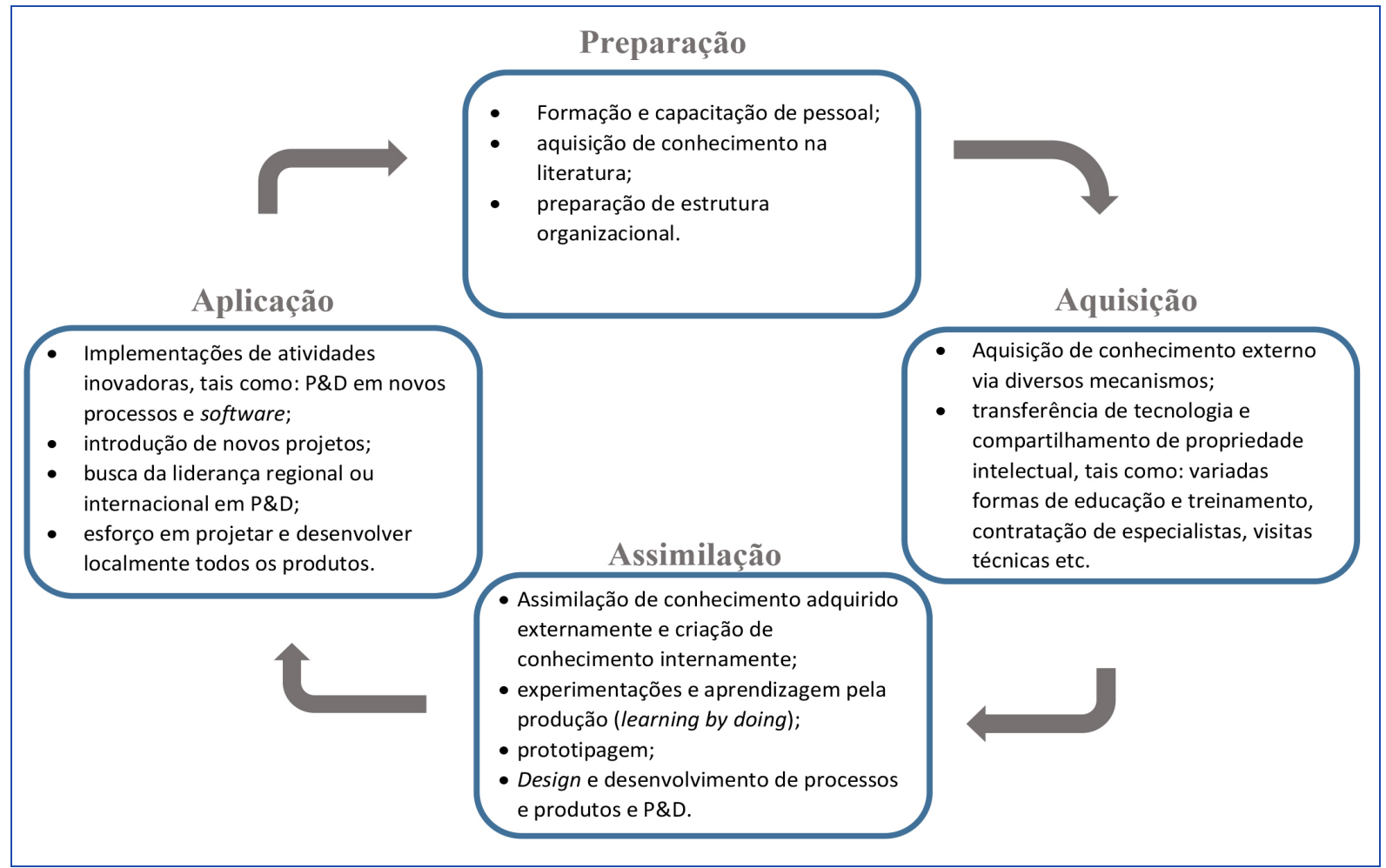

Fonte: Adaptada de Bell e Figueiredo (2012) e Kim (1998). 


\section{MÉTODOS}

Esta seção apresenta elementos chave do método do estudo, quais sejam: (i) estratégia da pesquisa; (ii) seleção do caso e (iii) coleta e análise de dados.

\section{Estratégia da pesquisa}

Com base na questão em torno da qual este estudo foi estruturado, foram utilizados critérios para identificar uma estratégia de pesquisa que viabilizasse a análise dos projetos selecionados. A metodologia envolveu um exame da indústria de defesanacional e internacional - e do EB durante a implementação dos projetos estudados, entre 1999 e 2016. Foi identificada, ao longo do período, a evolução dos níveis de acumulação de capacidades tecnológicas pelo EB na implementação dos projetos estudados. Primeiro, identificaram-se os níveis de capacidades tecnológicas no EB, no âmbito dos projetos. No segundo momento, analisou-se o papel dos processos subjacentes de aprendizagem tecnológica utilizados durante os projetos para a acumulação de capacidades tecnológicas.

\section{Seleção do caso}

Como mencionamos, o Brasil faz parte do grupo de países de economia emergente que tem buscado incentivar a indústria de defesa nacional (BITZINGER, 2013). Com isso, em 2008, o Brasil criou a Estratégia Nacional de Defesa e decidiu retomar a indústria de defesa como tema de enfoque de seus investimentos, como foi dito anteriormente. A Estratégia Nacional de Defesa trata de questões políticas e institucionais decisivas para a defesa do País, como os objetivos relacionados a maior participação do País em defesa (BRASIL, 2012).

Nesse contexto, o EB objetivava fornecer ao País o conhecimento tecnológico necessário para desenvolver seus próprios projetos na indústria de defesa. O primeiro passo para alcançar esse objetivo foi transformar a Infantaria Motorizada em Mecanizada e substituir a Viatura Blindada de Transporte de Pessoal (VBTP) Urutu e a Viatura Blindada de Reconhecimento (VBR) Cascavel, em uso desde 1980 (BASTOS JÚNIOR, HIGUCHI e BACCHI, 2015).

Dois importantes projetos de $\mathrm{P} \& \mathrm{D}$, desenvolvidos pelo $\mathrm{EB}$, atenderam ao objetivo do estudo. O projeto REMAX - um sistema de armas constituído de um reparo de metralhadora, com possibilidade de integração a uma viatura sobre rodas ou sobre lagartas - e o projeto TORC30 - um sistema de armas similar ao REMAX, para uma categoria superior de armamento, com utilização de um canhão calibre $30 \mathrm{~mm}$ - foram selecionados como objeto de análise neste estudo. Considerou-se relevante o estudo do projeto da Nova Família de Blindados sobre Rodas (NFBR), uma vez que permitiu uma importante acumulação de capacidades tecnológicas para o desenvolvimento dos projetos selecionados. Assim, para comprovar que a acumulação de capacidades tecnológicas ocorre por meio de diversos esforços em processos de aprendizagem tecnológica (FIGUEIREDO, 2015), o estudo investigou evidências das atividades do projeto NFBR, tendo foco de análise, no entanto, nos projetos REMAX e TORC30.

\section{Coleta e análise de dados}

Foram utilizados dados primários e secundários. Os dados primários foram coletados por meio de interações realizadas com participantes dos projetos e integrantes do EB. Os dados secundários foram coletados por meio da literatura disponível, como artigos científicos, apresentações e relatórios. Houve dificuldades na coleta de alguns dados, em virtude de o Exército não fornecer a maioria das informações ao público.

Com base nos dados primários e secundários coletados sobre os projetos estudados, o processo de análise objetivou expandir o entendimento sobre o assunto estudado e aumentar o potencial de impacto da pesquisa. Segundo Gil (2002), as pesquisas descritivas têm como objetivo primordial a descrição das características de determinada população ou fenômeno ou, então, o estabelecimento de relações entre variáveis. Já para Trivinos (1987), o estudo descritivo necessita de um conjunto de informações sobre o objeto de estudo, para que descreva os fatos e os fenômenos do cenário estudado. Seguindo Gil (2002), o aspecto explicativo tem como preocupação central identificar os fatores que determinam ou que contribuem para a ocorrência dos fenômenos, com o objetivo final de aprofundar o conhecimento da realidade, ao explicar a razão e o porquê dos fenômenos.

Especificamente, a análise de dados deu-se por meio da investigação das atividades desenvolvidas durante a implementação dos projetos selecionados. Desenvolveu-se uma escala de níveis de capacidades tecnológicas (Figura 4) e efetuou-se a 
classificação da evolução e da trajetória da acumulação de níveis de capacidades tecnológicas pelo EB ao longo do período estudado. Além disso, desenvolveu-se um modelo de ciclo de aprendizagem tecnológica para medir o papel e a influência do processo de aprendizagem tecnológica na acumulação de capacidades tecnológicas.

\section{Acumulação de Capacidades Tecnológicas nos Projetos REMAX e TORC30 no EB}

O propósito nesta seção é explicar como o EB, no âmbito dos projetos Reparo de Metralhadora Automatizado X (REMAX) e Torre Operada Remotamente e Estabilizada para Canhão $30 \mathrm{~mm}$ (TORC30), construiu e acumulou capacidades tecnológicas para inovar. Nesse intuito, inicialmente será examinada a acumulação de níveis de capacidades tecnológicas do EB no desenvolvimento dos projetos selecionados. Subsequentemente, investiga-se o papel dos processos subjacentes de aprendizagem tecnológica ao longo da acumulação de capacidades tecnológicas na implementação dos projetos.

\section{Acumulação de níveis de capacidades tecnológicas do EB na implementação dos projetos REMAX e TORC30}

Esta subseção apresenta de maneira descritiva a evolução da acumulação de níveis de capacidades tecnológicas pelo EB durante a implementação dos projetos NFBR, REMAX e TORC30. A seção está dividida em três subseções: Fase 0: Nova Família Blindada sobre Rodas (1999-2006); Fase 1: Reparo de Metralhadora Automatizado X (2006-2011); e Fase 2: Torre Operada Remotamente e Estabilizada para Canhão 30mm (2011-2016).

\section{Fase 0: nova família de blindados sobre rodas (1999-2006)}

A acumulação de capacidades tecnológicas no desenvolvimento de projetos para a força terrestre é um objetivo prioritário do EB (BASTOS JÚNIOR, HIGUCHI e BACCHI, 2015). Nesse cenário, nasceu o projeto da NFBR em 1999. A Figura 7 mostra a VBTP-MR Guarani, um blindado anfíbio com capacidade para 11 tripulantes. Bastos Júnior, Higuchi e Bacchi (2015, p. 27) apontam que:

O projeto foi desenvolvido nacionalmente pelo Exército, combinando investimentos da Financiadora de Estudos e Projetos (FINEP), por meio de ação conjunta dos Ministérios da Defesa e da Ciência e Tecnologia, desde o desenvolvimento do protótipo de maior risco até a produção de um lote piloto, proporcionando um cenário de diminuição de riscos tanto para o Exército, como para a empresa parceira. Destaca-se que esse arranjo, com aportes da FINEP e do EB, foi pioneiro, encontrando semelhanças somente no contemporâneo projeto Radar Saber M60.

\section{Figura 7}

Viatura Blindada de Transporte de Pessoal - Média de Rodas (VBTP-MR) Guarani

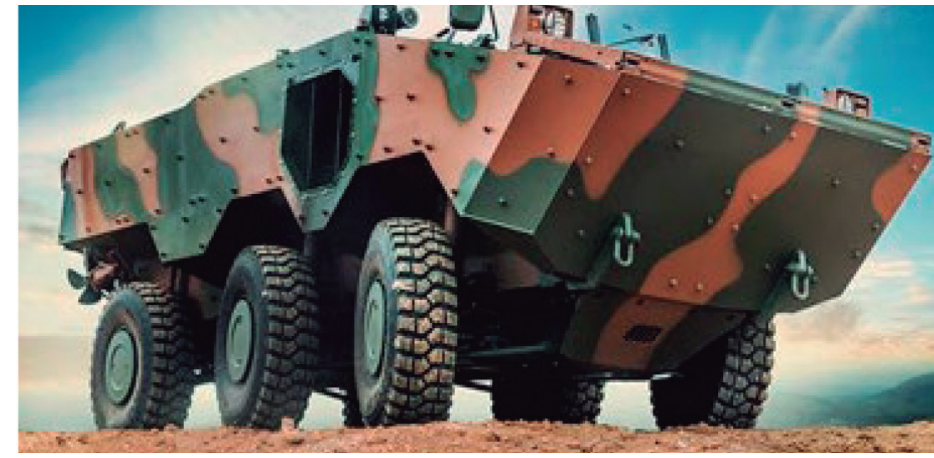

Fonte: IVECO Brasil (2013a).

O Exército elaborou os Requisitos Técnicos Básicos (RTB), o anteprojeto e o Estudo de Viabilidade Técnico-Econômica e tornou o projeto prioridade dentro da força. Foi criada uma estrutura organizacional ad hoc para a Gerência Técnica do projeto subordinada diretamente à chefia do Departamento de Ciência e Tecnologia (DCT) -, permitindo-lhe buscar consultorias com o Estado-Maior do Exército (EME) e o Centro de Instrução de Blindados (CIBId) sempre que necessário (BASTOS JÚNIOR; HIGUCHI e BACCHI, 2015). 
A empresa IVECO, detentora de um conhecimento técnico acumulado no desenvolvimento como projetista e fabricante de veículos de defesa, foi contratada como parceira. Na seleção, foi utilizado um mecanismo baseado em critérios objetivos e conduzido pelo DCT, a partir de propostas da Gerência Técnica, vinculados às diretrizes e premissas do projeto, dispensando a licitação por alta complexidade tecnológica e por interesse da defesa nacional (BASTOS JÚNIOR, HIGUCHI e BACCHI, 2015). Isso tornou o processo de seleção mais acertado e permitiu que fosse escolhida a empresa mais vantajosa para o projeto.

A IVECO incorporou soluções de mercado necessárias ao projeto e fabricou o primeiro protótipo, sob acompanhamento de uma equipe de absorção de conhecimentos e de transferência de tecnologia residente na empresa e diretamente ligada à Gerência Técnica do Exército (BASTOS JÚNIOR, HIGUCHI e BACCHI, 2015). Houve uma valiosa transferência de tecnologia por parte da IVECO, bem como a integração de um grupo de profissionais especializados ao projeto.

Por meio de testes realizados pelo Centro de Avaliações do Exército (CAEx), foram percebidas oportunidades e incorporadas à viatura outras características que permitiram cumprir as diretrizes estratégicas do mercado nacional e do Exército, entre elas: guarnição composta por motorista e atirador; softwares para gerenciamento do campo de batalha com interface com o sistema $C^{2}$ em combate, dados e imagens integrados à estrutura eletrônica da viatura e do sistema de armas; entre outras (BASTOS JÚNIOR, HIGUCHI e BACCHI, 2015).

A empresa Usiminas foi motivada a desenvolver o aço balístico - um aço de alta resistência, desenvolvido para atender os requisitos de impacto balístico, com características de aplicação para fins de defesa, incluindo a fabricação de veículos blindados -, visando observar a demanda da utilização deste material nas VBTP-MR Guarani (USIMINAS, 2018). A empresa Alltec Materiais Compostos foi motivada a desenvolver a proteção adicional externa Ultra Flex Fence (UFF) para ser equipada na VBTP-MR Guarani.

A IVECO elaborou o sistema logístico integrado (SLI) e forneceu ao Exército: treinamentos para operação e manutenção da viatura; conjuntos de ferramentas; manuais técnicos de operação; manuais técnicos de manutenção; catálogos de itens de suprimentos; reposição de todas as peças, fluidos, baterias e componentes (BASTOS JÚNIOR, HIGUCHI e BACCHI, 2015).

Em 2015, o Exército criou a Agência de Gestão e Inovação Tecnológica (Agitec), responsável por executar a gestão da inovação no processo de P\&D para obtenção de produtos de defesa e serviços inovadores, por meio de cooperação entre academia, governo e indústria, gerando um ambiente favorável ao incremento, compartilhamento de conhecimento e desenvolvimento de novos produtos e sistemas de defesa que privilegiem o uso de tecnologia dual (BRASIL, 2018b).

Os resultados obtidos no projeto da NFBR levaram a IVECO, por livre iniciativa, a implantar uma fábrica, em Sete Lagoas (MG), dedicada aos blindados Guarani, com capacidade instalada para produzir 140 viaturas por ano (BASTOS JÚNIOR, HIGUCHI e BACCHI, 2015), conforme demonstrado na Figura 8.

Figura 8

Fábrica da IVECO, em Sete Lagoas (MG), de produção da VBTP-MR Guarani

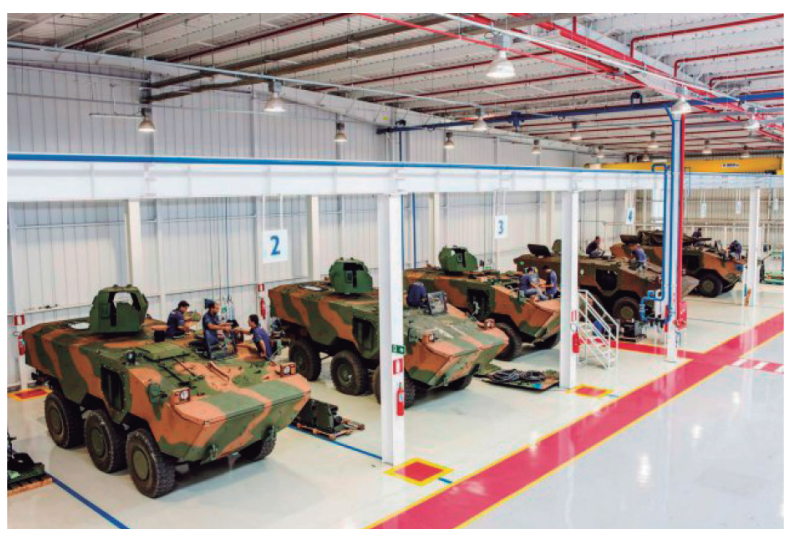

Fonte: IVECO Veículos de Segurança (2013b). 


\section{Fase 1: reparo de metralhadora automatizado X(2006-2011)}

Durante o projeto de P\&D da NFBR, o EB foi motivado a desenvolver o Reparo de Metralhadora Automatizado X (REMAX), para ser integrado à NFBR. A Figura 9 apresenta o REMAX, um sistema de armas constituído de um reparo de metralhadora, servoestabilizado, com acionamento elétrico e controlado remotamente por um operador localizado dentro da viatura. $\mathrm{O}$ REMAX foi concebido para a VBTP-MR Guarani, porém pode ser empregado também em outras plataformas com teto rígido e que suportem o seu peso, como as viaturas Urutu, M113 e Piranha.

Figura 9

Reparo de Metralhadora Automatizado X (REMAX)

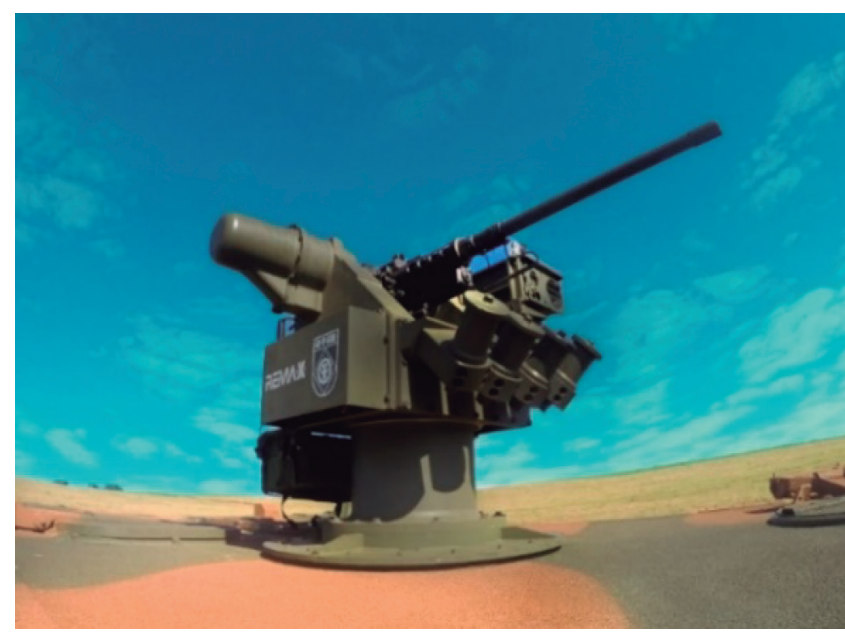

Fonte: Brasil (2016c).

O CTEx elaborou o projeto conceitual, priorizando, ao longo de suas fases, a possibilidade de diferentes configurações que atendessem as necessidades dos usuários. Foi contratada a Ares Aeroespacial e Defesa Ltda., uma empresa nacional com conhecimento acumulado no desenvolvimento de plataformas servoestabilizadas e experiência no fornecimento de sistemas militares para a Marinha do Brasil e Força Aérea Brasileira.

Uma infraestrutura com laboratórios, equipamentos adaptados e profissionais especializados estava disponível, assim como uma estrutura organizacional favorável à troca de conhecimentos entre os centros de pesquisa do EB e a empresa contratada. A Figura 10 e a Figura 11 mostram, de maneira consecutiva, o primeiro protótipo do REMAX (REMAX 1) e o seu painel de controle. Com a utilização das capacidades acumuladas no projeto NFBR, o REMAX 1 foi desenvolvido em dois anos e apresentado ao público sob uma estativa na Latin American Aero-Defense (LAAD) 2009. 
Figura 10

Primeiro protótipo do REMAX (REMAX 1)

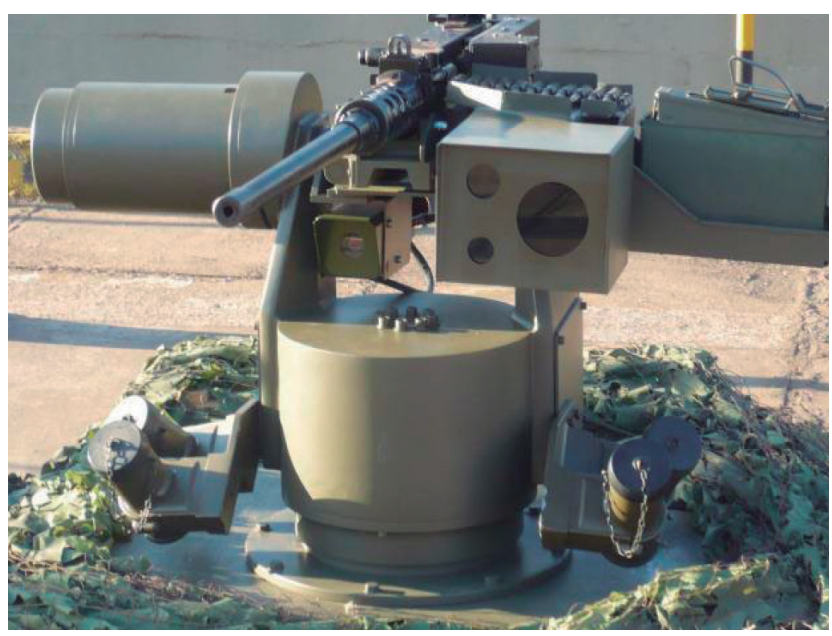

Fonte: Brasil (2016c).

Figura 11

Painel de controle do REMAX 1

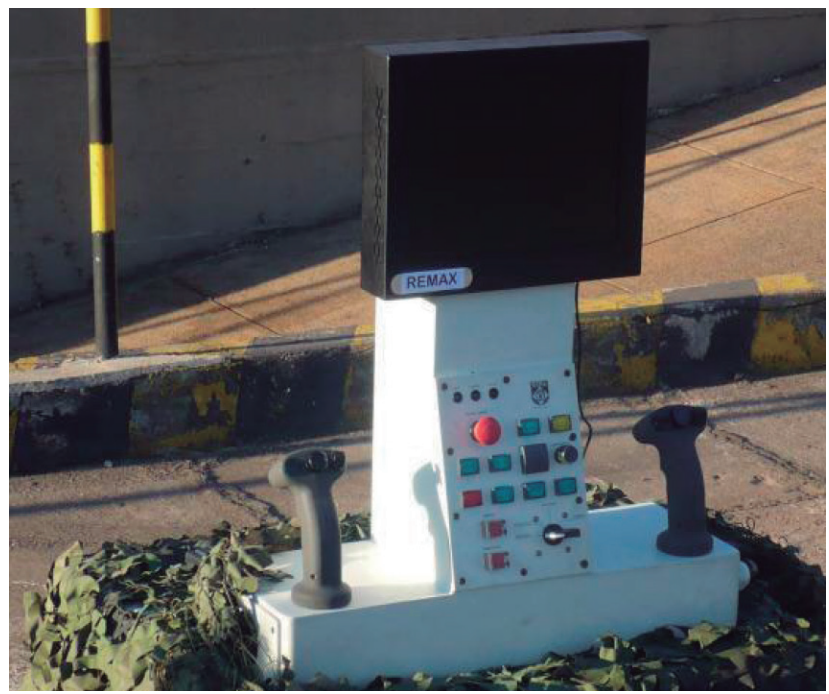

Fonte: Brasil (2016c).

O REMAX 1 foi implementado na VBTP Urutu e exposto na LAAD 2011, como mostra a Figura 12. Em 2012, o Instituto Nacional de Pesquisas Espaciais (INPE) realizou, de maneira satisfatória, no REMAX 1, testes de compatibilidade/susceptibilidade eletromagnética. No mesmo ano, foram também realizados os testes de estabilização, de rodagem, de tiro e climáticos. $\mathrm{O}$ CAEx realizou um elenco de ensaios da Apreciação do Protótipo, baseado no Memorial Descritivo do REMAX e nos Requisitos Técnicos Básicos da VBTP-MR Guarani. 


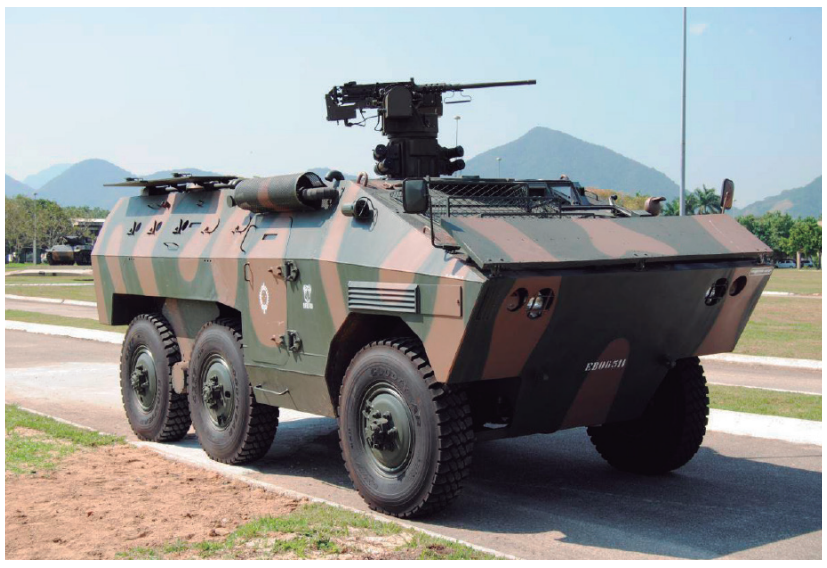

Fonte: Brasil (2016c).

Durante os testes realizados pelo CAEx, foram detectadas oportunidades de melhorias que poderiam ser realizadas, quais sejam: a implementação de tratamento superficial ao material, o aperfeiçoamento da qualidade da pintura e a adoção de telemetria laser. Foi estabelecido, então, o segundo contrato com a ARES para a obtenção do segundo protótipo do REMAX (REMAX 2), com o objetivo de agregar as oportunidades de melhoria que foram detectadas. O desenvolvimento do protótipo REMAX 2 durou um ano e foi submetido aos mesmos testes conduzidos pelo CAEX. Em 2012, o REMAX 2 foi instalado na Viatura Blindada de Patrulhamento e Emprego Dual (VBPED). Em 2013, houve a integração do protótipo do Remax 2 na VBTP-MR Guarani, que foi apresentado na LAAD 2013, como mostra a Figura 13.

Figura 13

Protótipo REMAX 2 integrado à VBTP-MR Guarani

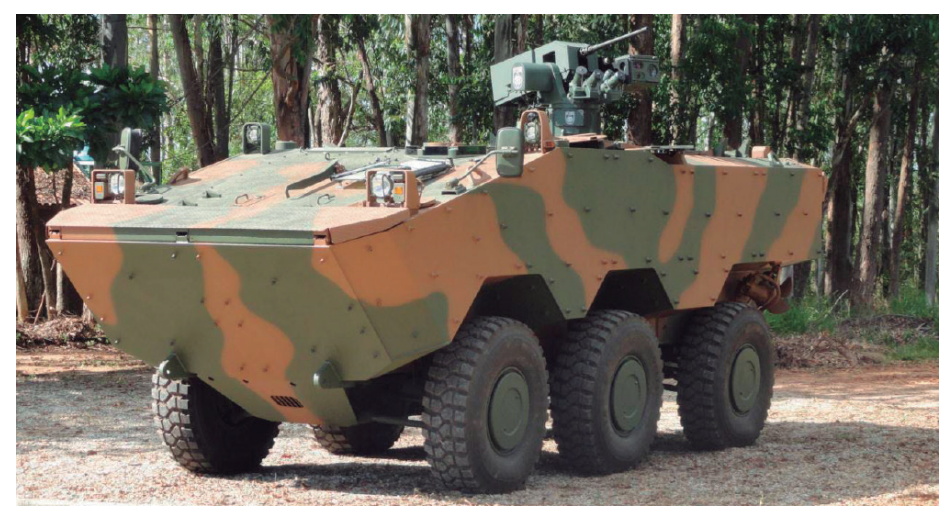

Fonte: Brasil (2016c).

A ARES foi contratada para o fornecimento e desenvolvimento de 81 unidades do lote piloto do REMAX (REMAX 3) e sua integração na VBTP-MR Guarani. As oportunidades de melhorias percebidas durante a apreciação do REMAX 2 foram implementadas no REMAX 3, quais sejam: rearme automático da metralhadora; utilização da metralhadora 12,7mm, possibilitando mais segurança ao usuário; rajada programável; implementação do contador de tiro e do computador balístico e, com isso, de funcionalidades como o Auto Tracking (ATT); introdução de partes internas comuns a outros sistemas de armas do mundo. 
O desenvolvimento do REMAX 3 durou um ano. O CAEX efetuou testes de desempenho em duas unidades, avaliou o manual de operação e o manual de manutenção fornecidos pela ARES. Em 2014, a ARES realizou a qualificação da integração do Lote Piloto REMAX 3 na VBTP-MR Guarani LED 67 - chassi 83 e habilitou a IVECO a proceder à instalação.

A Experimentação Doutrinária foi realizada na 15a Brigada de Infantaria Mecanizada (15a Bda Inf Mec), visto que já havia realizado a Experimentação da VBTP-MR Guarani e estava habilitada como Infantaria Mecanizada. Assim, já possuía uma infraestrutura preparada e pessoal especializado para receber as atividades. Em 2015, o REMAX 3 foi exposto na LAAD 2015, instalado na VBTP-MR Guarani, nas VTR 4x4 Tupi, LMV e Gladiador II totalmente operacional.

O CAEx, a ARES e o $33^{\circ}$ Batalhão de Infantaria Motorizado (33으 BI Mtz) realizaram avaliações complementares no REMAX integrado na VBPT-MR Guarani e encontraram não conformidades, principalmente em relação ao módulo optrônico e ao problema da necessidade de o remuniciador precisar sair do veículo para trocar o cofre de munição, uma vez que a viatura não possui uma escotilha de inspeção. Contudo uma pesquisa realizada pelos integrantes do projeto apontou que esta é uma característica presente nas principais estações de armas utilizadas pelos exércitos modernos, visto que somente uma estação de armas possuía municiamento interno no período de desenvolvimento do projeto.

Para solucionar o problema do módulo optrônico, uma equipe com membros da Diretoria de Fabricação (DF) e da ARES foram à fábrica da OIP Sensor Systems, na Bélgica, a fim de acompanhar os testes com este módulo e adquirir os conhecimentos necessários para a integração do REMAX à viatura. Em 2015, o REMAX 3 foi instalado na Viatura Piranha do Corpo de Fuzileiros Navais (CFN), como mostra a Figura 14.

Figura 14

REMAX 3 instalado na Viatura Piranha do Corpo de Fuzileiros Navais (CFN)

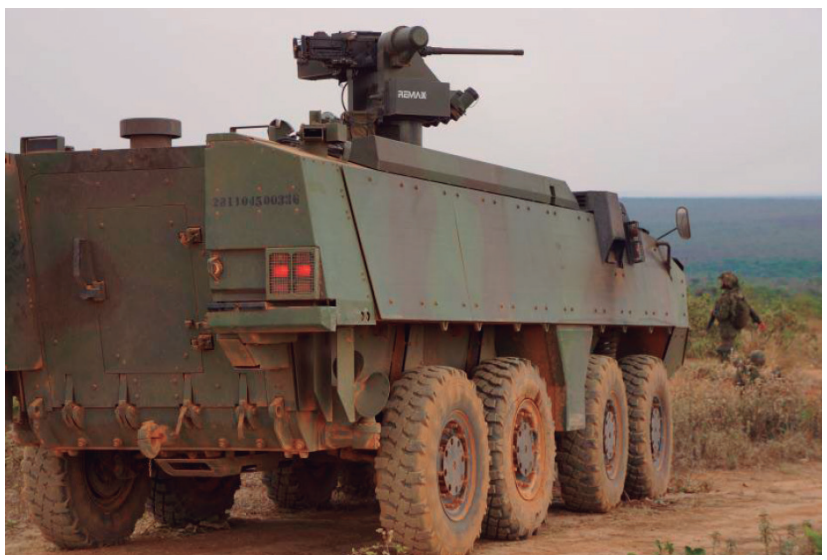

Fonte: Brasil (2016c).

Para a integração do REMAX, a ARES ficou responsável por componentes do kit de instalação e a IVECO, pelo anel de interface, pela caixa de distribuição de potência e pela realização da integração. Em 2016, a IVECO deu início às instalações do REMAX na VBTP-MR Guarani, em sua fábrica em Sete Lagoas (MG).

O CAEx realizou novos testes de performance. Ocorreram sugestões de modificações, algumas facilmente implementáveis, como no caso do auto-tracking, da estação do comandante e da modificação dos labels das chaves para melhorar a acurácia na identificação. Porém, outras sugestões demandariam uma mudança no projeto e poderiam ser implementadas no REMAX 4, como no caso do aumento da quantidade de munições no cofre e do fato de o operador ter de sair da viatura para o municiamento. Vale ressaltar que, diante do cenário dos exércitos mundiais, o REMAX está em similitude com a maioria dos sistemas de armas do mundo, com excelente desempenho, oferecendo maior segurança ao atirador e grande precisão nos tiros realizados. Como consequência, tem-se a redução da vulnerabilidade do atirador, a minimização dos danos colaterais, o aumento do poder de combate em operações noturnas e a economia de munição. A Figura 15 mostra o REMAX integrado na VBTP-MR 6x6 Guarani. 


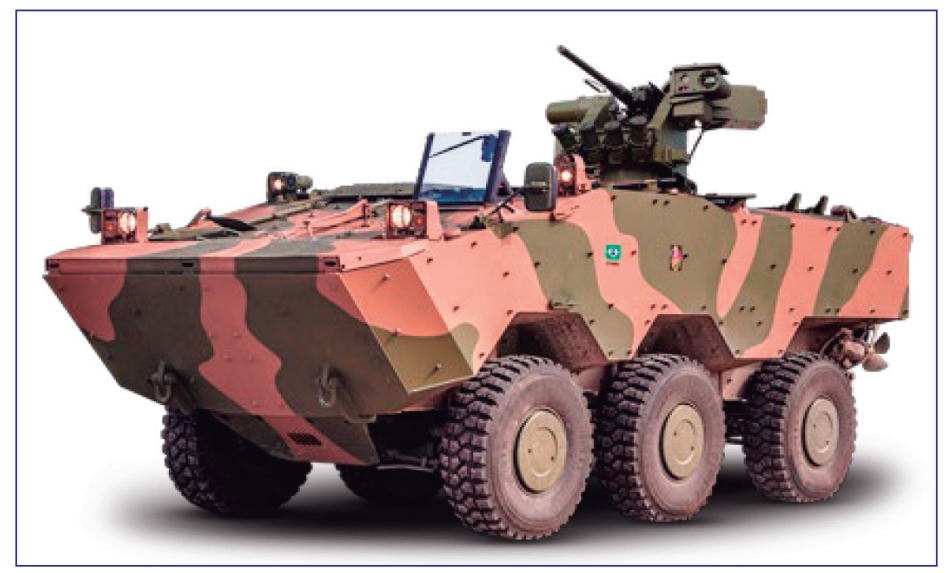

Fonte: ARES Aeroespacial e Defesa (2018).

\section{Fase 2: torre remotamente controlada e estabilizada para canhão 30mm (2011-2016)}

A capacidade intelectual e experiência acumuladas pelo Exército nos projetos antecessores motivaram a P\&D de um projeto similar ao REMAX para uma categoria superior de armamento, utilizando um canhão calibre $30 \mathrm{~mm}$. A motivação do projeto foi a necessidade de atender aos Requisitos Operacionais Básicos (ROB) da VBTP-MR Guarani, que previam que ela fosse dotada de um sistema de armas calibre $30 \mathrm{~mm}$ remotamente controlado, além da implementação no sistema do municiamento interno, sem expor o atirador, sugestão percebida na última avaliação do REMAX. O projeto aproveitaria o cenário oportuno de incentivo à $P \& D$ de sistemas de armas nacionais, além da infraestrutura laboratorial e pessoal capacitado resultantes dos projetos anteriores.

O CTEx elaborou o projeto conceitual e as Especificações Técnicas da torre artilhada com canhão 30x173mm NATO. Visando a uma nova parceria entre o Centro e a ARES, a empresa desenvolveu um projeto de uma plataforma inercialmente estabilizada para canhão $30 \mathrm{~mm}$, considerando que o conhecimento acumulado no desenvolvimento desta plataforma serviria como base para o projeto da TORC30. Contudo, quando a Ares foi comprada pela Elbit Systems, o Exército decidiu assinar um protocolo de intenções para aquisição de até 216 torres com canhão $30 \mathrm{~mm}$ UT30BR-ELBIT para VBTP-MR Guarani. Assim, o objetivo do projeto de desenvolver uma torre para canhão $30 \mathrm{~mm}$ para as VBTP-MR Guarani tornou-se irrelevante.

O CTEx buscou, então, um projeto alternativo para aplicação dos recursos já disponibilizados pela FINEP. O novo projeto teve como objetivo a obtenção de um sistema de armas com características tais que permitissem a aplicação dual do canhão alemão MK30-2/ABM da multinacional Rheinmetall. Trata-se de uma torre inovadora, pelo fato de ter um campo de elevação de -50 a +85 , o que permite o engajamento de alvos terrestres e aéreos de oportunidade. É a primeira torre remotamente controlada e estabilizada para canhão $30 \mathrm{~mm}$ no mundo com a possibilidade de engajar alvos terrestres e aéreos.

Em 2012, a ARES foi contratada para a P\&D da Torre Operada Remotamente e Estabilizada para Canhão 30 mm (TORC30). 0 projeto previa que a estação possuísse as seguintes funcionalidades: suportar um canhão calibre $30 \mathrm{~mm}$; permitir a pontaria em elevação e azimute do canhão; possibilitar a observação, reconhecimento e identificação de alvos durante o dia e a noite; realizar o tiro em movimento; operação do sistema realizada no interior da viatura, por meio de comandos eletrônicos.

Foi realizada uma aproximação do representante da Rheinmetall no Brasil, a fim de negociar a compra do canhão calibre $30 \mathrm{~mm}$ MK30-2/ABM, identificado como um dos poucos que permitiriam obter o efeito dual - alvos terrestres e aéreos. A Rheinmetall realizou visitas ao CTEx para inteirar-se do projeto, investiu na P\&D e aceitou vender o canhão pelo preço possível de ser coberto dentro do valor disponível no convênio da FINEP. Nas instalações da Rheinmetall, na Alemanha, foi realizado o teste de aceitação de fábrica do canhão. $O$ desenvolvimento do primeiro protótipo ocorreu em 2015. A Figura 16 apresenta uma configuração geral da TORC30. 
Figura 16

Configuração geral da Torre Operada e Estabilizada para Canhão 30 mm Rheinmetall MK30-2/ABM (TORC30)

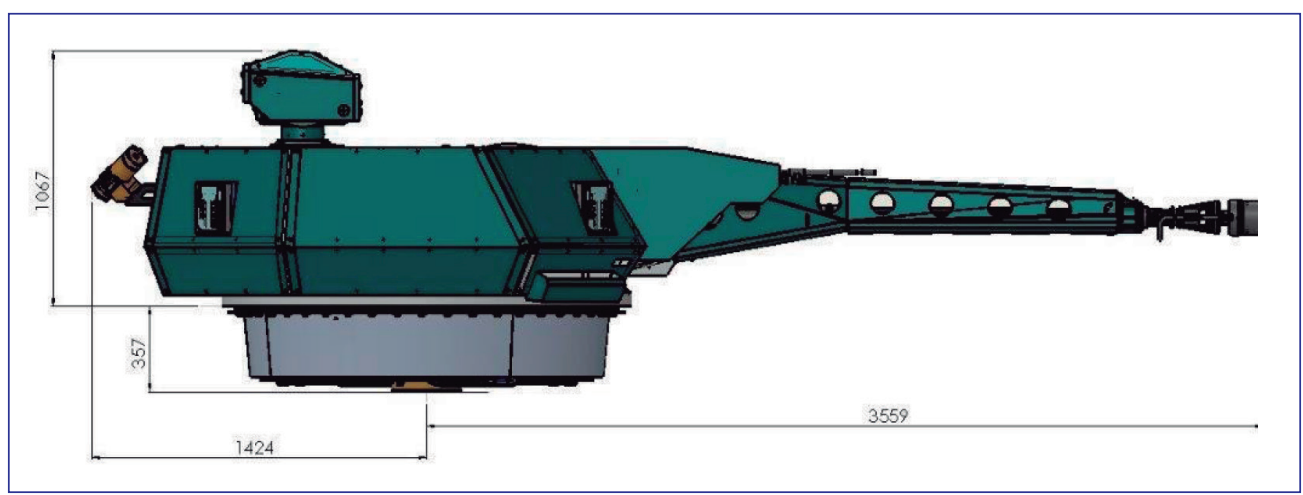

Fonte: Brasil (2016c).

No desenvolvimento da P\&D da TORC30, ocorreu a busca por condições de realizar a prototipagem de maneira mais rápida e desenvolver o design dos componentes do produto. O CTEx desenvolveu as interfaces necessárias ao funcionamento do canhão na estrutura da torre. Em 2014, foram realizados os testes em estativa pelo CAEx, visando verificar o correto funcionamento do sistema de alimentação da TORC30. Os resultados satisfatórios permitiram a consolidação do projeto detalhado do sistema de alimentação e o prosseguimento do projeto. Foram concluídas as etapas referentes a Especificações dos Requisitos, Projeto Preliminar, Protótipo Experimental e Projeto Detalhado. A Figura 17 mostra o primeiro protótipo operacional da TORC30 na fábrica da ARES.

Figura 17

Protótipo Operacional da TORC30

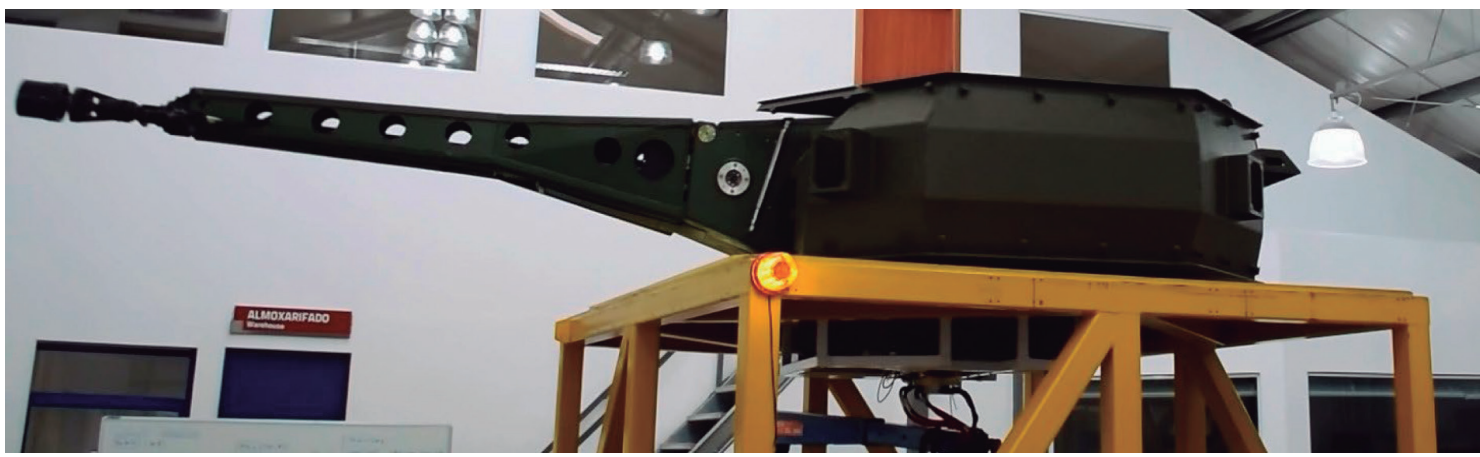

Fonte: Brasil (2016c).

A IVECO foi motivada a realizar um estudo de viabilidade técnica para a integração da TORC30 com a VBTP-MR Guarani $6 x 6$. Porém a IVECO informou ao CTEx que o estudo conceitual sumário indicava grande dificuldade na integração da TORC30 com a viatura, pois, diferente do REMAX, apenas afixado sobre o teto da VBTP-MR Guarani, a TORC30 requeria o corte no teto da viatura para que ficasse com perfil mais baixo. Assim, a IVECO realizou o estudo de viabilidade de uma viatura específica para receber a TORC30, a VBTP-MR Guarani/TORC30. Concluiu que havia necessidade de mais recursos para o prosseguimento do projeto. Em 2013, foi apresentado, na LAAD 2013, um filme com a nova concepção artística da TORC30 integrada na VBTP-MR Guarani, como mostra a Figura 18. 
Figura 18

TORC30 integrada à VBTP-MR Guarani

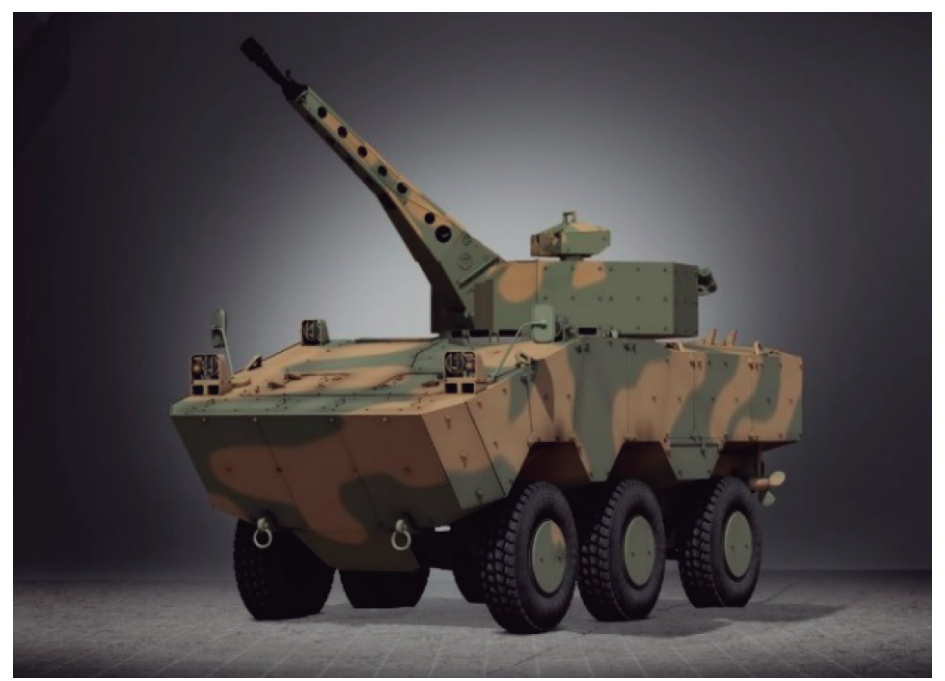

Fonte: Brasil (2016c).

\section{Papel dos processos de aprendizagem tecnológica na acumulação de capacidades tecnológicas} do EB na implementação dos projetos REMAX e TORC30

Considerando a importância dos mecanismos de aprendizagem tecnológica para a acumulação de capacidades tecnológicas inovadoras, esta subseção objetiva examinar a influência desses mecanismos pelo EB na implementação dos projetos selecionados. A subseção será dividida em três outras subseções: Fase 0: Nova Família de Blindados sobre Rodas; Fase 1: Reparo de Metralhadora Automatizado X e Fase 2: Torre Operada Remotamente e Estabilizada para Canhão 30mm.

\section{Fase 0: nova família de blindados sobre rodas (1999-2006)}

A Figura 19 mostra o ciclo de aprendizagem tecnológica do projeto da Nova Família de Blindados sobre Rodas (NFBR). Na etapa de preparação, o Exército procurou retomar o conhecimento acumulado nos projetos anteriores de viaturas blindadas desenvolvidos em parceria com a empresa Engesa, como a VBTP-MR Urutu, Cascavel e Osório (BASTOS JÚNIOR, HIGUCHI e BACCHI, 2015). O início do projeto também foi marcado pelo processo de seleção de tipos de profissionais necessários. A maioria dos engenheiros e profissionais do Exército não possuía experiência no desenvolvimento de viaturas blindadas, então a preparação dos profissionais ocorreu de duas formas: aquisição de conhecimento na literatura; envio de um grupo de profissionais para especialização nos Estados Unidos e na Alemanha. Por meio das interações proporcionadas pela estrutura organizacional ad hoc, que facilitou o compartilhamento de conhecimento entre os profissionais, o Exército realizou atividades como testes de performance e engenharia. 
Figura 19

Ciclo de aprendizagem tecnológica do projeto da Nova Família Blindada sobre Rodas (NFBR)

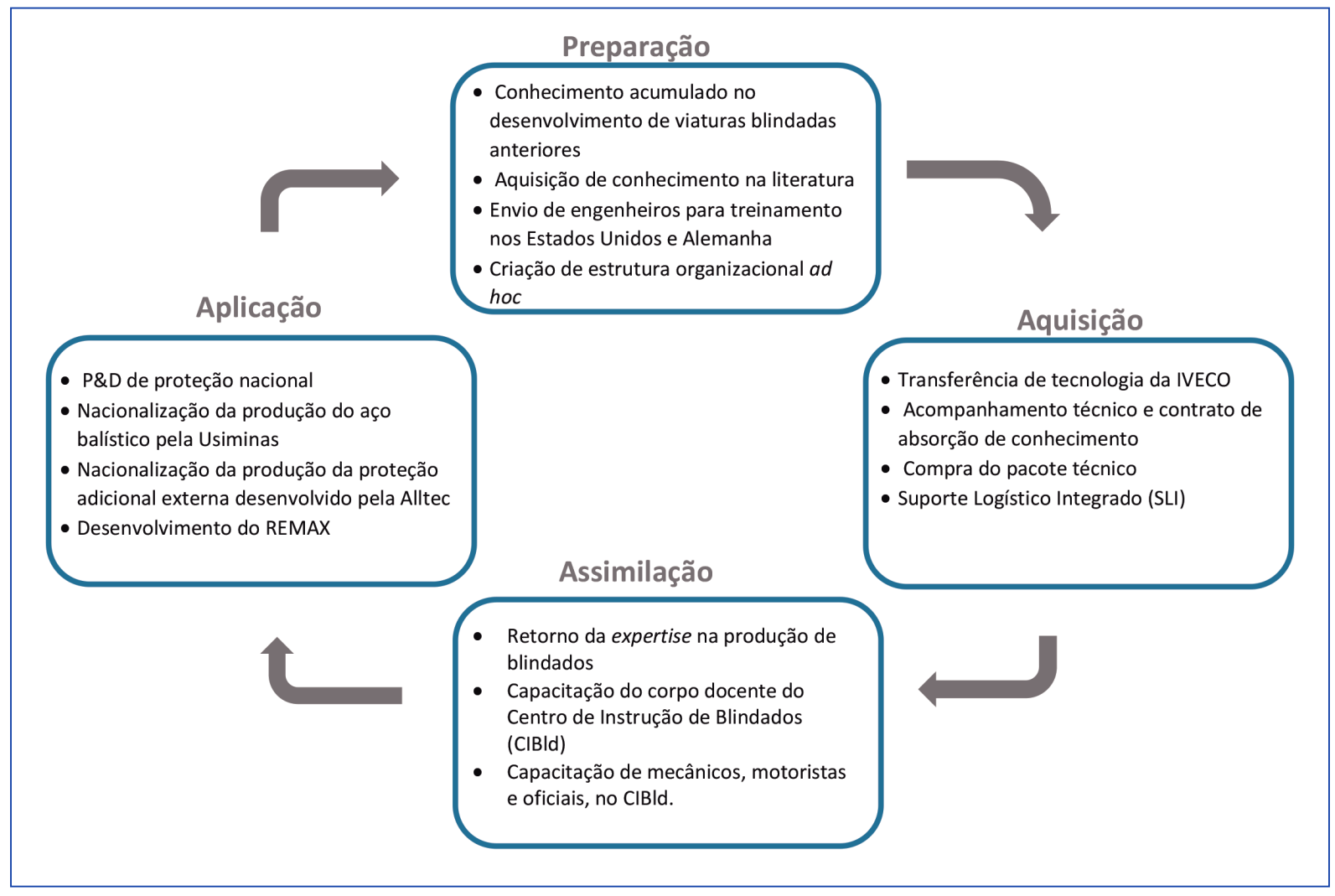

Fonte: Elaborada pelos autores.

$\mathrm{Na}$ etapa de assimilação, o EB procurou retomar a expertise adquirida no desenvolvimento e na produção de viaturas blindadas. $O$ desenvolvimento do projeto repercutiu em um extenso processo de capacitação de pessoal especializado no EB. Nesse contexto, o CIBld passou a ser responsável pela especialização de profissionais de viaturas blindadas e mecanizadas.

Foram realizados dois cursos para dois oficiais e cinco sargentos do CIBId, ministrados pelos profissionais da IVECO, a fim de habilitar o corpo docente para o ensino de manutenção da VBTP-MR Guarani. O primeiro curso foi de familiarização, uso e operação da viatura, com duração de duas semanas, sendo a primeira semana nas instalações do CAEx e a segunda, de atividades práticas, no CIBld. O segundo curso foi de manutenção da viatura, durou quatro semanas e ocorreu na nova fábrica da IVECO em Sete Lagoas (MG) (BASTOS JÚNIOR, HIGUCHI e BACCHI $(2015$, p. 36).

Em 2013, o ClBld realizou as atividades de capacitação de seu corpo docente para que pudessem treinar os profissionais do Exército. Após a capacitação dos seus profissionais, o CIBld passou a realizar, anualmente, a especialização de mecânicos de chassis e de sistemas de armas para todas as viaturas mecanizadas e blindadas existentes no Exército, além de cursos de operação das viaturas mecanizadas e blindadas; cursos de emprego tático de tropas mecanizadas e blindadas, e seções de instrução de blindados (BASTOS JÚNIOR, HIGUCHI e BACCHI, 2015). Essas atividades realizadas pelo CIBId capacitaram os profissionais do EB à implementação do Lote Piloto na 15a Brigada de Infantaria Motorizada e no 33으 Batalhão de Infantaria Mecanizado.

Na última etapa, a de aplicação, o Exército obteve experiência em P\&D e acumulou conhecimento no desenvolvimento e produção de blindados. O projeto da NFBR não buscou apenas a obtenção de novos materiais por aquisição ou preparação. Não se tratou de continuar a fazer o mesmo com um novo material; o que se buscou, em última instância, foi a obtenção de um fazer diferente, o desenvolvimento e a incorporação das novas capacidades exigidas pela guerra moderna (BASTOS JÚNIOR, HIGUCHI e BACCHI, 2015). 


\section{Fase 1: reparo de metralhadora automatizado X(2006-2011)}

A Figura 20 mostra o ciclo de aprendizagem tecnológica do projeto do Reparo de Metralhadora Automatizado X (REMAX). Na etapa de preparação, o Exército preparou e utilizou as capacidades adquiridas no desenvolvimento do projeto NFBR. Conforme descrito na subseção "Acumulação de níveis de capacidades tecnológicas do Exército Brasileiro na implementação do projeto REMAX", o projeto da NFBR exigiu um intenso processo de capacitação de profissionais, investimento em infraestrutura e adaptação do sistema organizacional do Exército. O que quer dizer que o EB já havia utilizado mecanismos de aprendizagem e acumulado capacidades no projeto anterior.

Na etapa de aquisição, foi realizada transferência de tecnologia da ARES para o EB. Novamente, assim como ocorreu na Fase 0 , o Exército buscou transferência de tecnologia de uma empresa fornecedora que possuía nível de capacidade tecnológica mais elevado. Após a ARES ser comprada pela Elbit Systems, em 2010, passou por um valioso processo de transferência de tecnologia e aquisição de conhecimento externo nos campos técnico e organizacional. Sendo a Elbit Systems uma dominadora de conhecimento relacionado aos vários aspectos de P\&D e produção de sistemas de defesa, a ARES acumulou novos conhecimentos, aumentando seu nível de conhecimento prévio. Além disso, após a aquisição, houve um considerável investimento na infraestrutura da ARES. Nesta etapa, uma parte da equipe foi até a fábrica da OIP Sensor Systems, na Bélgica (conforme apontado na subseção "Acumulação de níveis de capacidades tecnológicas do Exército Brasileiro na implementação do projeto REMAX"). Por meio dos conhecimentos externos adquiridos por esses profissionais, foi possível a realização da integração do REMAX na viatura.

Figura 20

Ciclo de aprendizagem tecnológica do projeto do Reparo de Metralhadora Automatizado X (REMAX)

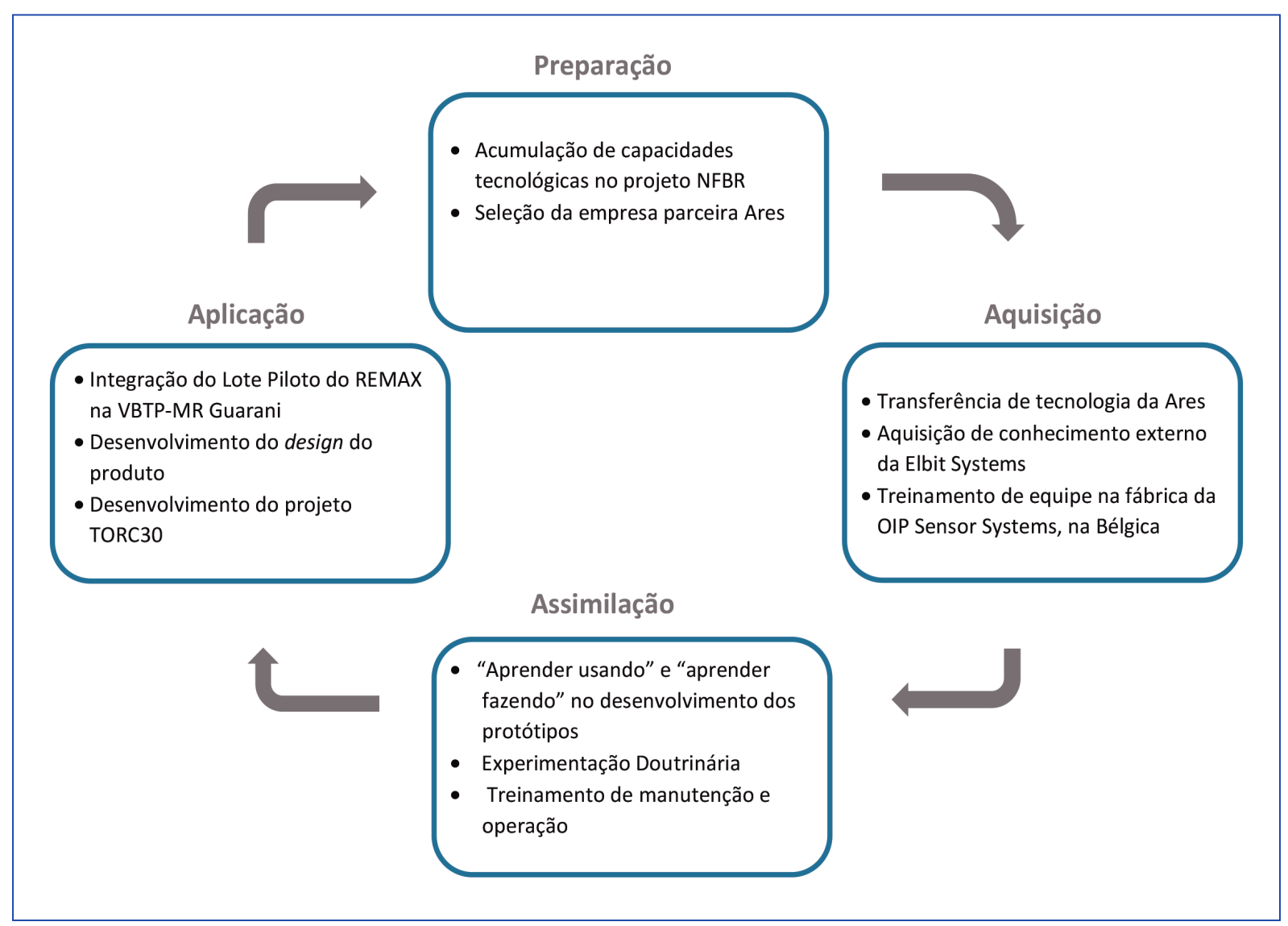

Fonte: Elaborada pelos autores. 
Na etapa de assimilação, o conhecimento tácito e a experiência trazidos pelo processo de transferência de tecnologia da ARES e da Elbit Systems tiveram de ser aprendidos, principalmente pelos profissionais especializados do CTEx. A etapa foi marcada pelas várias formas de aprender usando e aprender fazendo utilizadas no desenvolvimento dos primeiros protótipos. As atividades de Experimentação Doutrinária foram realizadas com facilidade, uma vez que o CIBld já havia capacitado um grupo de mecânicos, motoristas e oficiais no projeto NFBR. Para aumentar a equipe, integrantes do CTEx realizaram um novo treinamento para operação e manutenção com dez alunos no CAEx, com 10 alunos.

Na etapa de aplicação, a ARES realizou a qualificação da integração do lote piloto do REMAX na VBTP-MR Guarani e habilitou a IVECO a realizar a instalação. Durante as etapas do projeto, a ARES acumulou capacidade tecnológica suficiente para estruturar o primeiro centro de excelência no desenvolvimento e fabricação de estações de armas e torres de artilharia no Brasil. A parceria do CTEx com a ARES deu ao Brasil a capacidade de projetar e desenvolver Sistemas de Armas Remotamente Controlados (SARC) e tornar-se referência internacional.

\section{Fase 2: torre operada remotamente e estabilizada para canhão 30mm (2011-2016)}

A Figura 21 mostra o ciclo de aprendizagem tecnológica do projeto da Torre Operada Remotamente e Estabilizada para Canhão 30 mm (TORC30). Na etapa de preparação, o CTEx havia acumulado capacidades tecnológicas no desenvolvimento dos projetos anteriores. Uma infraestrutura laboratorial já estava disponível para dar suporte à maioria das atividades do projeto, além de pessoal capacitado e um sistema organizacional capaz de absorver e internalizar conhecimento. A ARES desenvolveu uma plataforma inercialmente estabilizada para canhão $30 \mathrm{~mm}$, considerando que o conhecimento acumulado serviria como base para a TORC30.

Na etapa de aquisição, o CTEx foi beneficiado com uma transferência de tecnologia da ARES, que compartilhou $50 \%$ de sua propriedade intelectual, $100 \%$ do pacote técnico, sua infraestrutura laboratorial, adquiriu componentes e equipamentos e disponibilizou a plataforma inercialmente estabilizada para canhão $30 \mathrm{~mm}$ para estudo. O CTEx ficou responsável por disponibilizar sua infraestrutura laboratorial e seus recursos humanos, preparar o projeto para a P\&D, além de adquirir no exterior o armamento principal e seus acessórios. Além disso, a aproximação da ARES e do CTEx com a Rheinmetall, em visitas da empresa ao Centro, visitas dos profissionais do projeto à fábrica da Rheinmetall, na Alemanha, e a obtenção do pacote de dados técnicos do canhão possibilitaram a aquisição de conhecimento pelos profissionais envolvidos.

Na etapa de assimilação, a ARES utilizou o conhecimento acumulado pelos seus engenheiros por meio da transferência de tecnologia da Rheinmetall para desenvolver as interfaces necessárias ao funcionamento do canhão na estrutura da torre. Nesta etapa, os conhecimentos acumulados pelos profissionais da ARES e do CTEx foram utilizados e proporcionaram condições de realizar a prototipagem de maneira mais rápida e desenvolver o design dos componentes e as interfaces necessárias ao funcionamento do canhão. Na etapa de aplicação, o CTEx e a ARES acumularam capacidade de projetar e desenvolver SARC de médio calibre e capacidade de projetar e desenvolver sistemas de alimentação de munição de SARC, com amplo campo de elevação (-5ㅇ a +85우). 
Figura 21

Ciclo de aprendizagem tecnológica do projeto da Torre Operada Remotamente e Estabilizada para Canhão 30 mm (TORC30)

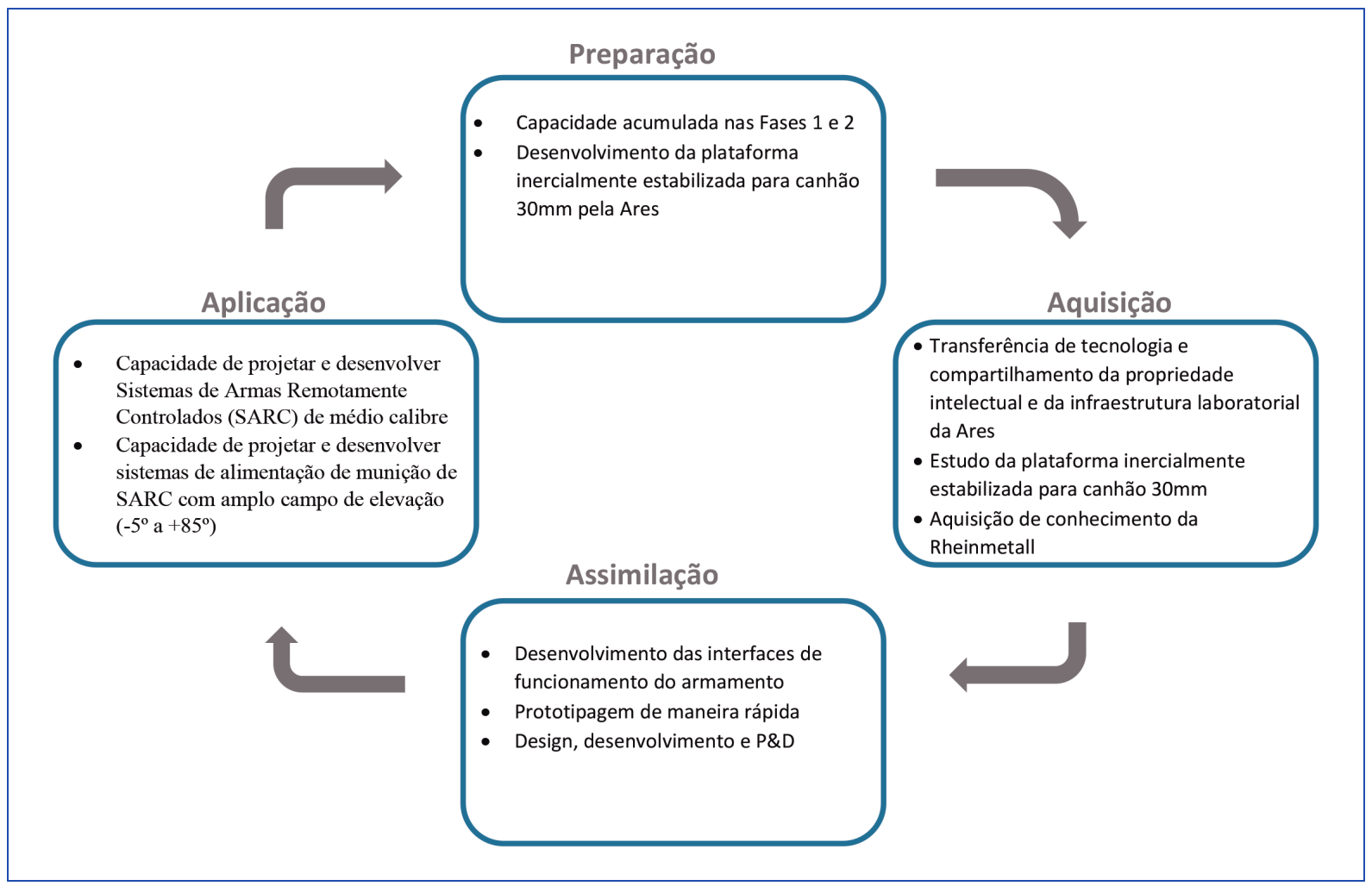

Fonte: Elaborada pelos autores.

\section{DISCUSSÕES E CONCLUSÕES}

Esta seção se dedica a analisar a discussões das principais evidências encontradas no estudo, assim como as conclusões e recomendações para estudos futuros e políticas públicas direcionadas para a indústria.

\section{Discussões das principais evidências do estudo}

Neste estudo demonstrou-se que, ao longo do desenvolvimento dos projetos examinados, o EB conseguiu evoluir e alcançar níveis de capacidades tecnológicas mais elevadas, no âmbito das atividades desenvolvidas nos projetos. Essas capacidades inovadoras foram acumuladas por intermédio de diversas estratégias deliberadas e efetivas no processo subjacente de aprendizagem tecnológica. A acumulação de capacidades tecnológicas inovadoras gerou resultados positivos, no âmbito do EB e na indústria de defesa nacional. Portanto é possível afirmar que o investimento público em projetos de P\&D, no âmbito das Forças Armadas, pode contribuir integralmente para o crescimento e fortalecimento da indústria de defesa do Brasil.

Sinteticamente, o estudo examinou como o EB conseguiu acumular capacidades tecnológicas inovadoras, por meio de processos subjacentes de aprendizagem tecnológica, no âmbito das atividades desenvolvidas nos projetos REMAX e TORC30. A fim de aprofundar, de forma sucinta e detalhada, a trajetória de acumulação de capacidades tecnológicas estudada, a Figura 22 apresenta a evolução de níveis de capacidades tecnológicas e do processo subjacente de aprendizagem tecnológica pelo EB nas atividades específicas desenvolvidas nos projetos, durante o período de 1999 a 2016.

A Figura 22 demonstra que, no início do projeto REMAX, o Exército possuía nível de capacidade tecnológica de inovação básica no âmbito das atividades desenvolvidas nos projetos, e que, ao final do projeto TORC30, conseguiu elevar-se ao nível de capacidade tecnológica de inovação avançada. Essa elevação derivou dos esforços realizados em processos de aprendizagem 
tecnológica. Contudo foi evidenciado que a elevação de níveis de capacidades tecnológicas não se deu unicamente pelo desenvolvimento dos projetos analisados. O EB havia utilizado mecanismos de aprendizagem e acumulado capacidades tecnológicas no projeto NFBR. Com isso, percebe-se que a acumulação de capacidades tecnológicas está longe de ser um processo isolado e repentino. A elevação de níveis de acumulação de capacidades tecnológicas ocorre por meio de diversos esforços no processo de aprendizagem tecnológica (FIGUEIREDO, 2015).

Conforme se observa na Figura 22, em 1999, no início do desenvolvimento do projeto Guarani, o Exército possuía nível de capacidade de produção no âmbito das atividades desenvolvidas nos projetos REMAX e TORC30. Durante as etapas do projeto, o Exército realizou atividades como: retomada da expertise na produção de blindados; P\&D do protótipo e nacionalização da produção. Para isso, engajou-se na utilização de processos de aprendizagem, adquirindo, por exemplo, conhecimento na literatura disponível, enviando profissionais especializados para cursos nos Estados Unidos e na Alemanha. Buscou, com isso, retomar a expertise na produção de viaturas blindadas, realizando transferência de tecnologia da IVECO e capacitando o corpo docente do CIBId.

Figura 22

Evolução de níveis de capacidades tecnológicas e do processo de aprendizagem tecnológica pelo Exército Brasileiro, entre 1999 e 2016

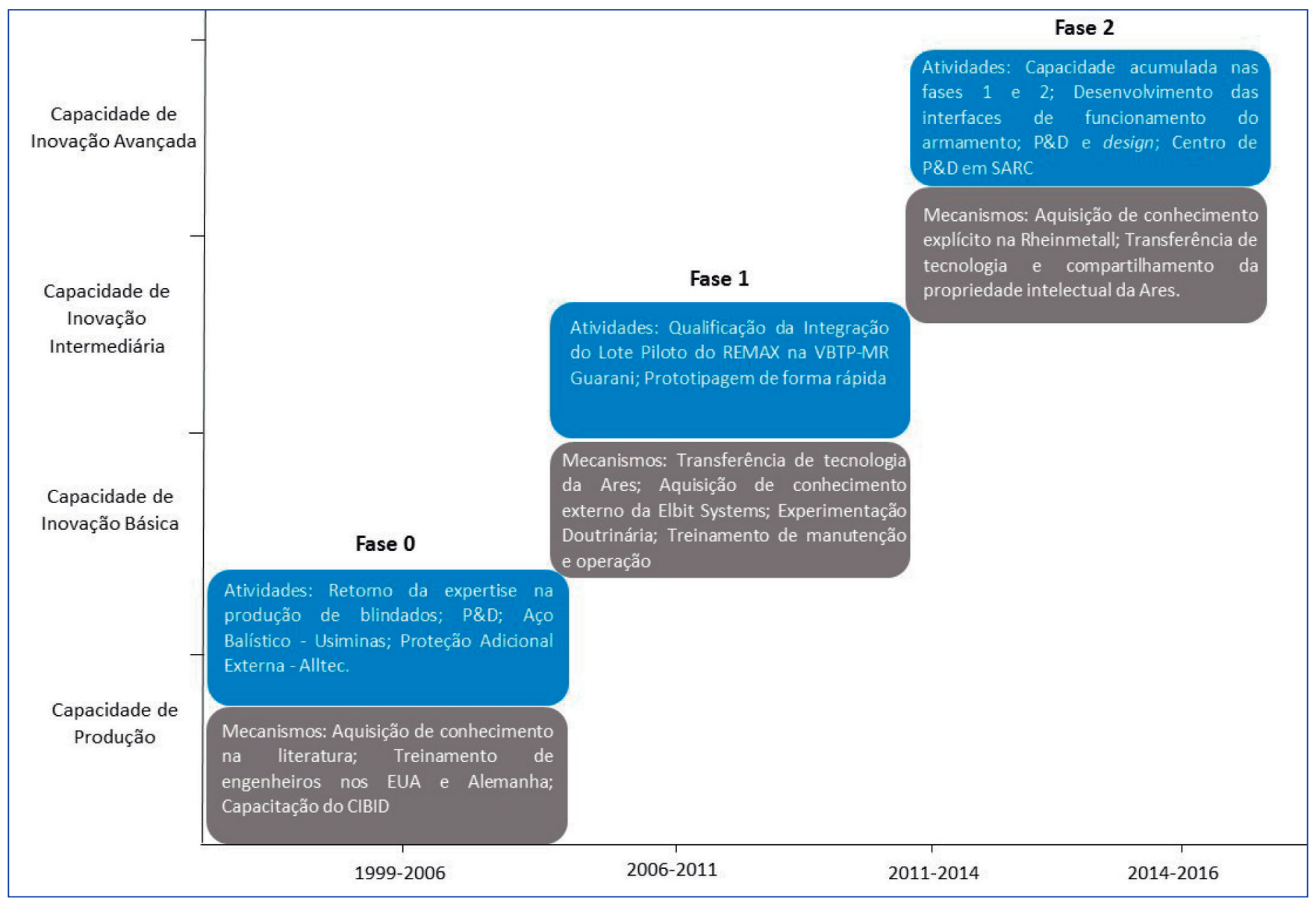

Fonte: Elaborada pelos autores.

A Figura 22 aponta ainda que, no período entre 2006 e 2011, no início do projeto REMAX, o Exército acumulou capacidade de inovação básica e intermediária, no âmbito das atividades desenvolvidas, nos projetos REMAX e TORC30. O Exército desenvolveu, por exemplo, planejamento e coordenação formal; aprimoramento sistemático das especificações da viatura; prototipagem de maneira rápida e a qualificação da integração do Lote Piloto do REMAX na VBTP-MR Guarani. Para isso, engajou-se na 
utilização de mecanismos de aprendizagem, como a transferência de tecnologia da ARES; a aquisição de conhecimento externo da Elbit Systems; a experimentação doutrinária do REMAX e o treinamento de manutenção e operação pelo CAEx.

Por fim, a Figura 22 revela que, no período entre 2011 e 2014, no projeto TORC30, o Exército acumulou capacidade de inovação avançada, no âmbito das atividades desenvolvidas nos projetos REMAX e TORC30. O Exército foi capaz de desenvolver as interfaces de funcionamento da TORC30; P\&D e design e estruturar um centro de excelência de P\&D em SARC. Para isso, engajou-se em utilizar processos de aprendizagem, tais como: aquisição de conhecimento explícito na Rheinmetall; transferência de tecnologia e compartilhamento da propriedade intelectual da ARES. Portanto o EB conseguiu evoluir seu nível de capacidades tecnológicas, no âmbito das atividades desenvolvidas, até o nível de capacidade tecnológica avançada, que apresenta inovações para o País. Contudo não conseguiu alcançar o nível de capacidade tecnológica inovadora de liderança mundial, que implementa inovações para o mundo, abrindo oportunidades para a entrada de novos negócios.

Em síntese, aplicando as estratégias para analisar as atividades desenvolvidas nos projetos REMAX e TORC30, este estudo encontrou resultados que podem elevar a compreensão atual sobre o processo de acumulação de capacidades tecnológicas: 1) os projetos REMAX e TORC30 beneficiaram-se da acumulação de capacidades tecnológicas do projeto NFBR; 2 ) as atividades desenvolvidas no processo de aprendizagem tecnológica foram a fonte para a acumulação de capacidades tecnológicas durante a implementação dos projetos, obedecendo os conceitos apresentados por Figueiredo (2015), segundo o qual as capacidades tecnológicas são construídas e acumuladas por processos de aprendizagem tecnológica; 3) o processo de aprendizagem tecnológica na implementação dos três projetos obedeceu o modelo de ciclo de aprendizagem apresentado por Kim (1998), de acordo com o qual projetos de P\&D desenvolvidos em países de economias emergentes são constituídos pelas etapas: preparação, aquisição, assimilação e aplicação.

Conclui-se que o desenvolvimento dos projetos estudados permitiu a elevação do nível de capacidade tecnológica, no âmbito das atividades desenvolvidas nos projetos REMAX e TORC30, tanto do EB como das empresas parceiras, sobretudo da ARES. O REMAX foi o primeiro reparo de metralhadora remotamente controlado e estabilizado desenvolvido e produzido no Brasil. Apesar de já existirem reparos similares no mundo, as tecnologias integradas ao produto são dominadas por poucos países, principalmente com relação à estabilização do sistema de armas, que permite operar o sistema de maneira eficaz com a viatura em movimento. Com a evolução do REMAX até a versão 3, a ARES mostrou possuir um sistema técnico e físico bastante engajado em pesquisa, além de um capital humano com pleno conhecimento do sistema e dos requisitos operacionais do equipamento estabelecidos pelo Exército.

Com base no conhecimento acumulado durante a P\&D do REMAX, foi possível desenvolver a TORC30, a primeira torre que permite o engajamento de alvos terrestres e aéreos de oportunidade no mundo. Para realizar a integração da torre, houve a necessidade de desenvolver um sistema de alimentação de munição específico capaz de operar em diferentes ângulos de elevação. $O$ sistema de estabilização também é dominado por um grupo seleto de países no mundo. Pode-se afirmar que a parceria CTEx-ARES fez o Brasil tornar-se uma referência internacional em desenvolvimento de SARC (catch-up) em dez anos. Com o desenvolvimento dos projetos, o EB alcançou seu objetivo de modernização da frota atual, contando com mais de 300 unidades dos blindados Guarani, e entrega planejada de 2.044 unidades. Além de realizar a modernização da tropa atual do EB, foram exportadas 10 unidades da viatura para o Líbano em 2017 (SIPRI, 2019).

\section{CONCLUSÕES E RECOMENDAÇÕES}

Neste estudo foram examinados a evolução da acumulação de capacidades tecnológicas para inovação e o papel dos subjacentes processos de aprendizagem tecnológica na implementação dos projetos REMAX e TORC30, desenvolvidos pelo EB. A questão foi examinada com base em evidências empíricas primárias, coletadas no âmbito do EB, e secundárias, encontradas na literatura disponível. Foi desenvolvida uma escala de níveis de capacidades tecnológicas para analisar a acumulação de capacidades tecnológicas e um modelo de ciclo de aprendizagem tecnológica para analisar o papel do processo de aprendizagem tecnológica durante os projetos.

O estudo apontou que, ao longo de 17 anos, o EB moveu-se por níveis de capacidades inovadoras até atingir o nível de capacidade de inovação avançada ao fim do projeto TORC30, no âmbito das atividades desenvolvidas nos projetos REMAX e TORC30. Contudo observou-se que, além do EB, demais empresas do país foram beneficiadas e conseguiram alcançar níveis 
mais elevados de capacidades tecnológicas com o desenvolvimento dos projetos. Especificamente, os resultados encontrados se alinham a estudos anteriores, que indicaram como o investimento público em projetos de P\&D na indústria de defesa contribuem de forma positiva e significativa para as demais indústrias do País.

Frequentemente, a indústria de defesa é alvo de uma visão, restrita e equivocada, de que sua produção é voltada estritamente para armamento bélico, sem contribuição significativa para o desenvolvimento tecnológico e econômico dos países. Como se discutiu neste artigo, a acumulação de capacidades tecnológicas na indústria de defesa gera um transbordamento tecnológico para as demais indústrias do país. A indústria de defesa contribui, em sua grande maioria, com elementos de elevada tecnologia, visto que possui relação estreita com projetos de pesquisa, desenvolvimento e inovação. Tais evidências são importantes para estimular, em âmbito nacional, estratégias de inovação voltadas às particularidades da indústria de defesa. Um exemplo seria buscar inovação e transbordamento tecnológico que, aliados, beneficiem o desenvolvimento industrial no Brasil.

Vale destacar que este estudo se dedicou a analisar as implicações do processo de acumulação de capacidades tecnológicas e do papel dos processos subjacentes de aprendizagem tecnológica pelo EB no desenvolvimento dos projetos. Recomenda-se que estudos futuros examinem as implicações da acumulação de capacidades tecnológicas relacionadas aos indicadores de performance, tais como: performance operacional (produtividade, consumo etc.), performance ambiental e performance econômica. 


\section{REFERÊNCIAS}

Associação Brasileira das Indústrias de Materiais de Defesa e Segurança - ABIMDE. Relação Geral de Empresas credenciadas como ED \& EED. 2018. Disponível em: <http://www.abimde.org.br/informative/eed>. Acesso em: 11 fev. 2019.

ANDRADE, R. F.; FIGUEIREDO, P. N. Dinâmica da acumulação de capacidade tecnológica e inovação em subsidiárias de Empresas Transnacionais (ETNS) em economias emergentes: a trajetória da Motorola Brasil. Revista de Administração e Inovação, São Paulo, v. 5, n. 3, p. 73-92, 2008.

ARES AEROESPACIAL E DEFESA. REMAX. 2018. Disponível em: <http:// ares.ind.br//new/pt/sistemas-terrestres/remax.php>. Acesso em: 22 out. 2018.

BASTOS JÚNIOR, P. R. ; HIGUCHI, H.; BACCHI, R. O Projeto Guarani. Verde Oliva, v. 4, n. 227 p. 8-40, abr. 2015.

BELL, M.; FIGUEIREDO, P. N. Building Innovative Capabilities in Latecomer Emerging Market Firms: Some Key Issues. In: AMANN, E.; CANTWELL, J. (Eds.). Innovative Firms in Emerging Market Countries. Oxford: Oxford University Press, 2012. p. 24-110.

BELL, M.; PAVITT, K. Technological accumulation and industrial growth: Contrasts between developed and developing countries. Industrial and Corporate Change, v. 2, n. 2, p. 157-210, 1993.

BELL, M.; PAVITT, K. The development of technological capabilities: technology and international competitiveness. In: HAQUE, I. et al. Trade, technology and international competitiveness. 2. ed. Washington: The World Bank, 1995.

BITZINGER, R. A. Revisiting Armaments Production in Southeast Asia: New Dreams, Same Challenges. Contemporary Southeast Asia, v. 35, n. 3, p. 369-394, 2013

BRASIL. Estratégia Nacional de Defesa. In: BRASIL, M. DA D. (Ed.). Política Nacional de Defesa e Estratégia Nacional de Defesa. Brasília, DF: Ministério da Defesa do Brasil, 2012.

BRASIL. Agenda Tecnológica Setorial (ATS). Panorama Econômico Setorial - Defesa. 1. ed. Brasília, DF: Agência Brasileira de Desenvolvimento Industrial (ABDI), 2016a.

BRASIL. Dispêndio nacional em ciência e tecnologia - C\&T. 2016b. Disponível em: <http://dados.gov.br/dataset/indicadores-nacionaisde-ciencia-tecnologia-e-inovacao/resource/7a9bded0-756b-44d0abdb-dd8fcd4b977e>. Acesso em: 24 out. 2018.

BRASIL. Panorama Econômico Setorial - Defesa. Brasília, DF: Agência Brasileira de Desenvolvimento Industrial (ABDI), 2016c.

BRASIL. Índice Nacional de Preços ao Consumidor Amplo - IPCA. Séries Históricas. 2018a. Disponível em: <https://www.ibge.gov. br/estatisticas-novoportal/economicas/precos-e-custos/9256-

indice-nacional-de-precos-ao-consumidor-amplo.html?=\&t=serieshistoricas>. Acesso em: 4 fev. 2018.

BRASIL. Sobre a Agitec. 2018b. Disponível em: <http://www.dct. eb.mil.br/index.php/nu-agitec>. Acesso em: 22 out. 2018.

BRASIL. Orçamento e Finanças. 2019. Disponível em: <https://www. defesa.gov.br/orcamento>. Acesso em: 29 set. 2019.

CORREA FILHO, S. L. S. et al. Panorama sobre a indústria de defesa e segurança no Brasil. BNDES Setorial, Rio de Janeiro, n. 38, p. 373408, set. 2013.
CORRÊA, G. A Política de Defesa do Brasil no século XXI. Coleção Meira Mattos: Revista das Ciências Militares, v. 8, n. 31, p. 29-38, 2014.

CUNHA, I. C. B.; NOGUEIRA, R. J. B. O comércio mundial de armas e a exportação bélica do Brasil. Revista Geonorte, v. 8. n. 28, p. 178-190, maio 2017. Disponível em: <http://www.periodicos. ufam.edu.br/revista-geonorte/article/view/3516>. Acesso em: 19 set. 2019.

DOSI, G. Sources, Procedures, and Microeconomic Effects of Innovation. Journal of Economic Literature, v. 26, n. 3, p. 1120-1171, 1988.

DOSI, G. Mudança técnica e transformação industrial: a teoria e uma aplicação à indústria dos semicondutores. Campinas: Unicamp, 2006.

DOWNES, E. R. Defense technology transfer: programmatic and practical considerations. SeminárioD ed. Rio de Janeiro: LAAD Latin America Aero \& Defence - Conference \& Exhibition, 2009.

DUNNE, J. P.; BRADDON, D. Economic impact of military R\&D. 2008. Bruxelas: [s.n.]. Disponível em: <https://www.flemishpeaceinstitute. eu/sites/vlaamsvredesinstituut.eu/files/files/reports/vvi_web_ rapport_militairerend_en.pdf>. Acesso em: 4 out. 2019.

FIGUEIREDO, P. N. Technological learning and competitive performance. Cheltenham: Edward Elgar, 2001.

FIGUEIREDO, P. N. Gestão da Inovação: conceitos, métricas e experiências de empresas no Brasil. 2. ed. Rio de Janeiro: LTC, 2015.

FIGUEIREDO, P. N. et al. Imperativo do fortalecimento da competitividade industrial no Brasil. 1. ed. Rio de Janeiro: FGV Editora, 2018.

GIL, A. C. Como elaborar projetos de pesquisa. 4. ed. São Paulo: Atlas, 2002.

IVECO BRASIL. Veículos de Defesa. 2013a. Disponível em: <https:// www.iveco.com/Brasil/Institucional/Pages/Veiculos-de-Defesa.aspx>. Acesso em: 22 out. 2018.

IVECo Veículos de SEguRANÇA. Veículos de Defesa: Detalhamento do Processo. 2013b.Disponível em: <http://www. ivecoveiculosdefesa.com.br/site-root/index.html\#prettyPhoto>. Acesso em: 22 out. 2018.

JOERDING, W. Economic growth and defense spending: Granger Causality. Journal of Development Economics, v. 21, n. 1, p. 35-40, 1986.

KIM, L. Crisis Construction and Organizational Learning: Capability Building in Catching-up at Hyundai Motor. Organization Science, v. 9, n. 4. 1998.

KOLLIAS, C. Defence spending and growth in Turkey 1954-1993: A causal analysis. Defence and Peace Economics, v. 8, n. 2, p. 189204, 1997.

LEE, K.; LIM, C. Technological regimes, catching-up and leapfrogging: findings from the Korean industries. Research Policy, v. 30, n. 3, p. 459-483, mar. 2001.

LESKE, A. Inovação e Políticas na Indústria de Defesa Brasileira. [s.I.] Universidade Federal do Rio de Janeiro (UFRJ), 2013.

LESKE, A. Interação, Inovação e Incentivos na Indústria de Defesa Brasileira. Revista Política Hoje, v. 24, n. 1, p. 33-56. 2015. 
MIRANDA, E. C.; FIGUEIREDO, P. N. Dinâmica da Acumulação de Capacidades Inovadoras: Evidências de Empresas de Software no Rio de Janeiro e em São Paulo. RAE - Revista de Administração de Empresas, v. 50, n. 1, p. 75-93, 2010.

MOLAS-GALLART, J. Which way to go? Defence technology and the diversity of "dual-use" technology transfer. Research Policy, v. 26, n.3, p. 367-385. 1997.

NEGRETE, A. C. A. et al. Mapeamento da Base Industrial de Defesa. Brasília, DF: Agência Brasileira de Desenvolvimento Industrial: Instituto de Pesquisa Econômica Aplicada, 2016.

NELSON, R. R.; WINTER, S. G. An Evolutionary Theory of Economic Change. Cambridge: Harvard University Press, 1985.

Organisation for Economic Co-operation and Development - OECD. Information technology outlook-highlights. In: ORGANISATION FOR ECONOMIC CO-OPERATION AND DEVELOPMENT, 2002, Paris. Proceedings... Paris: OECD, 2002.

Organisation for Economic Co-operation and Development - OECD. Stat. 2018. Disponível em: <https://stats.oecd.org/>. Acesso em: 22 out. 2018.

RAVARA, R. L. F. O Reequipamento e a Indústria de Defesa - Subsídios para uma Política de Armamento. Nação e Defesa, v. 2, p. 115-145, 2001.
Stockholm International Peace Research Institute - SIPRI. SIPRI Yearbook 2015, Armaments, Disarmament and International Security. Solna, Sweden: Stockholm International Peace Research Institute (SIPRI), 2015.

Stockholm International Peace Research Institute - SIPRI. SIPRI Military Expenditure Database, SIPRI Top 100SIPRI. 2016. Disponível em: <https://www.sipri.org/databases/armsindustry>. Acesso em: 27 set. 2019.

Stockholm International Peace Research Institute - SIPRI. Banco de dados de transferências de armas. 2019. Disponível em: <https:// www.sipri.org/databases/armstransfers>. Acesso em: 27 set. 2019.

Stockholm International Peace Research Institute - SIPRI. SIPRI Military Expenditure Database | SIPRI. 2019. Disponível em: <https://www. sipri.org/databases/milex/>. Acesso em: 27 set. 2019.

TIAN, N. et al. Trends in world military expenditure, 2017. Solna: SIPRI, 2018.

TRIVINOS, A. N. S. Introdução à pesquisa em ciências sociais: a pesquisa qualitativa em educação. São Paulo: Atlas, 1987.

Usinas Siderurgicas de Minas Gerais - USIMINAS. Aço Balístico. 2018. Disponível em: <https://www.usiminas.com/blog/senti-orgulho-deser-brasileiro/>. Acesso em: 22 out. 2018.

Luiz Henrique Abreu Dal Bello

ORCID: https://orcid.org/0000-0002-7634-7014

Chefe da Seção de Armamento e Munição e Gerente do Grupo de Armamento e Munição do Centro Tecnológico do Exército Brasileiro, Rio de Janeiro

- RJ, Brasil. E-mail: dalbello.henrique@eb.mil.br

Paulo N. Figueiredo

ORCID: https://orcid.org/0000-0002-5857-8126

Ph.D pelo Science Policy Research Unit (SPRU), University of Sussex, Reino Unido; Criador e Coordenador, desde 1999, do Programa de Pesquisa em Aprendizagem Tecnológica e Inovação Industrial no Brasil na Escola Brasileira de Administração Pública e de Empresas da Fundação Getulio Vargas (FGV EBAPE); Professor titular da Fundação Getulio Vargas (FGV EBAPE), Rio de Janeiro - RJ, Brasil. E-mail: paulo.figueiredo@fgv.br

Thainá Ballero dos Anjos de Almeida

ORCID: https://orcid.org/0000-0002-3729-4626

Bolsista de Iniciação Científica (PIBIC) na Escola Brasileira de Administração Pública e de Empresas da Fundação Getulio Vargas (FGV EBAPE), Rio de Janeiro - RJ, Brasil. E-mail: thaina.almeida@fgv.br 